\title{
Coordinated Markets, School-to-Work Linkages, and Labor Market Outcomes in the European Union
}

\author{
Thomas A DiPrete and Joanna Chae \\ Columbia University
}

March 4, 2021

This research was supported with research funds provided by Columbia University. We acknowledge helpful comments from Christina Ciocca Eller, Benjamin Elbers, Michael Hout, Lane Kenworthy, Heike Solga, and Meir Yaish. These data were analyzed under a license agreement with Eurostat. 


\begin{abstract}
A large literature in both sociology and political science has theorized about the importance of country differences in skill formation systems for labor market outcomes. Focusing on twenty-one European countries, this paper establishes that countries differ in the strength of the pathways that connect educational credentials to the occupational structure, though there is considerable variability in the country rankings of the strength of individual pathways. Pathway strength matters for the quality of occupational matching, for employment and earnings, and for the earnings gap between well matched and less well-matched workers. In general, the total effects of local linkage strength are to raise earnings and to lower unemployment risk, though positive total effects of local linkage on earnings are concentrated at the lower tertiary and nontertiary educational levels. Suggestive evidence that pathway effects are stronger in high-linkage countries exists for male and for older female workers, and the results also support the hypothesis that local linkage is more protective against unemployment in high linkage countries. However, consistent differences between high-linkage and lowlinkage countries within educational levels are elusive. Thus, while macro-structural effects may be important, the principal difference among countries appears to be in the extent and distribution of pathway strength leading from educational credentials to occupations.
\end{abstract}




\section{Introduction}

Countries differ in the effect of family background on educational attainment (Shavit, Arum, and Gamoran 2007; Pfeffer 2008), but country differences in educational inequality do not correlate perfectly with country differences in labor market inequality (Solga 2012). This happens because, as Busemeyer (2014) argues, countries differ in how educational outcomes are connected to labor market positions and in the wage and earnings returns to those positions. An important question in both the sociological and the political science literatures on skill formation systems is whether countries sort into theoretically meaningful clusters or along dimensions that capture the most important institutional similarities and differences, most notably the distinctions between strong or weak vocational educational systems, between coordinated and liberal market economics, or between diversified or binary higher educational systems (Shavit and Müller 1998; Arum, Gamoran, and Shavit 2007; Hall and Soskice 2001b). But do these clusters and dimensions, which seemingly apply well to countries held up as "ideal types" in their institutional structure, usefully characterize the macro-structure of industrialized countries in general? If so, do they matter for the process of selection into educational and training programs, and do they influence the consequences of educational credentials for labor market outcomes?

Evidence that membership in one or the other of these theoretically-derived clusters is associated with systematic differences in labor market outcomes remains tentative, with the supporting evidence typically in the form of cross-country regressions or correlations between country characteristics and a measure of unemployment or wage or educational mobility or income inequality (Müller and Shavit 1998; Pfeffer 2008; Van de Werfhorst 2011; Gift and Wibbels 2014; Busemeyer 2014; Jerrim and Macmillan 2015). This work has considerably advanced our understanding, but its focus has been on institutional differences at the level of countries rather than of pathways that lead from specific educational outcomes to specific labor market positions. This work has under-appreciated the extent to which institutional differences ascribed to countries may matter differently for different educational outcomes. Indeed, our understanding is still limited about how the matching of credentials to jobs varies across industrial countries and whether this variation is consistent with theoretical schemes for distinguishing the skill formation systems of different countries.

DiPrete et al. (2017), Bol et al. (2019), and Elbers, Bol, and DiPrete (2021) have found that pathway structure matters for the value of educational credentials in the labor market. They showed that pathways differ in strength both within and between countries and that country differences vary depending on the credential in question. They also showed 
that the effects of pathway structure work largely through their impact on the extent and consequences of matching between educational credentials and labor market positions. However, the evidence contained in these papers cannot address the question of whether theoretical groupings accurately capture the pattern of similarities and differences across industrialized countries, because their work focused on only three arguably idealtypical countries: Germany, France, and the U.S. These results do not answer the question whether the theoretically postulated country clusters in the skill formation literature correspond to empirical differences in the strength of linkage between educational credentials and occupations. They also do not answer the question whether macro-structural differences matter for labor market outcomes apart from their association with local pathway structure.

In this paper, we examine the variation in pathway structure across a set of twenty one European countries using direct measures of linkage strength between educational and labor market outcomes. We focus on Europe both because European countries typically differentiate fields of study at the upper secondary as well as the tertiary level of education and because they have comparable data that has been assembled into the European Union Labour Force Survey (EU LFS). We find that clusters of countries based on the empirical structure of linkage conform only loosely to the theoretical groupings that have been proposed to describe skill formation systems. Countries, moreover, exhibit considerable internal variation in the strength of their pathways.

We furthermore find evidence that macro structure matters net of its association with the strength of specific educational pathways, frequently though not uniformly to enhance the impact of pathway strength on labor market outcomes. In general, however, pathway effects are more important than are country effects on outcomes. From a policy perspective, the combination of within-country heterogeneity of pathway strength and the dominance of pathway effects over country effects is encouraging news; it implies that reform efforts can be focused at the level of specific pathways instead of more challenging reforms to the system as a whole.

\subsection{Theories about Skill Formation, Employment, and Wages}

While especially focused on institutional similarities and differences, the skill formation literature has ties to foundational work on human capital. A core theoretical distinction was made by Becker (1962) between general human capital which, he argued, is useful to many employers, and specific human capital, which is more useful to the firm that provides it than it is to other firms. Becker also observed that schools can provide human capital that 
is specific to particular occupations such as barber or medical doctor, and that on-the-job training can be specific to an industry or occupation as well as to a firm. Becker's early work left open the possibility that institutional arrangements could affect how training is provided and its consequences for economic performance and for social mobility, but these connections were not developed.

This gap in human capital theory was filled by a sophisticated comparative literature in both sociology and political economy, which argued that countries differ systematically in the distribution of skills, the source of their training, and the consequences of the social organization of training. Maurice, Sellier, and Silvestre (1986) compared the social foundations of training in French and German manufacturing and concluded that the two countries differ in how general and specific training are provided; they saw the educational system in France as providing largely general training and then sorting workers by level of education into jobs of different status and earnings. The specific training for these jobs was then provided by firms in what Maurice et al called an organization space. In contrast, Germany provided specific occupational training for manufacturing jobs through a dual system of training offered coterminously by schools and employers in a "qualificational space" that sorted workers into specific occupations based on their credentials.

The comparative educational project organized under the CASMIN ("Comparative Analysis of Social Mobility in Industrial Societies") framework by Shavit and Müller (1998) built on the arguments of Maurice, Sellier, and Silvestre (1986) about the importance of "qualificational spaces" created by educational systems that emphasized vocational specificity. The CASMIN project added additional dimensions taken from the work of Allmendinger (1989) concerning the extent of national standardization of educational provision and the amount of stratification via tracking systems in the same or separate schools. The fourth dimension in the CASMIN theoretical scheme was the extent of "credential inflation," operationalized as the proportion of a cohort that obtained a tertiary degree. Shavit and Müller argued that the rate of tertiary education was important because of its potential impact on the value of secondary school credentials in a world in which workers compete for jobs on the basis of the level of their educational attainment as well as on the specificity of their occupational skills.

The group of "varieties of capitalism" (VoC) political economists organized by Hall and Soskice (2001) have examined how the "institutions of the political economy" - the skill formation system along with the systems of industrial relations, corporate governance, inter-firm relations, and intra-firm coordination - differ across countries, how the process of "co-evolution" produced these differences, and what their implications are for national performance. The major difference in the two country clusters that are most clearly de- 
lineated by their arguably dualist theoretical scheme (Crouch 2005; Kenworthy 2006) is between liberal market economies - epitomized by the United States — and coordinated market economics, of which Germany is the prime example. 1 Whether a coordinated or a liberal market economy works better in terms of macroeconomic performance depends on the extent to which these institutional systems are complementary (Hall and Soskice 2001b; Hall and Gingerich 2009). 2 Our focus is not on macroeconomic performance but rather on the skill-formation system and its stratification impact. Nonetheless, the VoC literature is relevant for our purposes because skill formation systems have played such a prominent role in VoC theory.

As Powell and Solga (2010) have argued, the comparative literature has generally been limited by a tendency to focus either on non-tertiary vocational educational systems or on tertiary educational systems without achieving a satisfactory theoretical integration of these two levels. Comparative sociology and the VoC literatures have, however, partially converged on applying the same basic distinctions of academic vs. vocational vs. comprehensive systems from the study of secondary school systems to the tertiary sector. This approach supports a theoretical distinction between higher educational systems that are unified, systems that are diversified, and higher educational systems that are binary (Arum, Gamoran, and Shavit 2007; Goedegebuure et al. 1996). Unified tertiary systems are those dominated by a single type of institution, i.e., the research university. Binary systems, in contrast, organize tertiary-level vocational education in second tier tertiary institutions, while diversified systems are less stratified; their second tier consists both of occupationally oriented programs and programs that potentially lead to academic education via transfer or continuation at upper tertiary institutions.

These ideas are clarifying and help us understand the historical development of tertiary educational systems and their connection with secondary school level vocational education. It is also notable that European countries have attempted through a combination of the Bologna and the Copenhagen processes to create a new European model for skill formation that combines a European competitor to the Anglo-American higher education system and the European - especially Germanic — model of vocational education and training (VET). However, there is still a considerable distance between the forces of standardization embedded in these processes and the actual organization of skill formation sys-

\footnotetext{
${ }^{1}$ Busemeyer (2014) proposed a third group of countries, which he called "statist," in which the state marginalized employers in the provision of school based vocational education and training systems at the secondary and later also at the tertiary level.

${ }^{2}$ For this reason an "institutional coherence" dimension - whether the major coordinating institutions of a country are similarly close to the liberal market or the coordinated market model - has sometimes been used to distinguish countries within and between these major clusters in terms of macro-economic performance (Kenworthy 2006).
} 
tems within the countries themselves (Powell and Solga 2010; Powell, Bernhard, and Graf 2012). Moreover, none of these schemes directly address the occupational consequences of the higher educational system or whether the same theoretical clusters developed out of a focus on manufacturing industries, skilled manual labor, and vocational education apply when the full educational system is considered.

\subsection{The Grouping and Scoring of Countries}

The theoretical schemes discussed above imply either groupings or scorings of countries in terms of the principal characteristics of training regimes to identify countries that are similar or dissimilar (Kenworthy 2006). In practice, however, it has been difficult to accomplish conceptually powerful and empirically useful classifications across the population of industrialized countries. To be sure, some countries have been fairly secure in their position as polar or ideal types, with Germany and the U.S. being examples in the VoC literature and Germany and France being examples in the CASMIN project. At the same time, most other industrialized countries countries lack this "ideal typical" status and are often dealt with in ambiguous or contradictory ways depending on the analyst in question. Even for the countries with ideal-typical status, messy empirical realities get in the way. For example, liberalization theorists such as Streeck (2009) and Glyn (2007) argued that global forces have eroded the institutional arrangements among the state, employers, schools, and labor unions that characterize the training regimes of coordinated market economies. Other scholars note diverging trends of resisting liberalization that in some cases move in the direction of a dual system, where some workers are protected and others not, and in other cases embrace a combination of market coordination mechanisms along with social insurance via active labor market policies (Thelen 2012).

Hall and Soskice (2001a) placed the USA, the UK, Australia, Canada, New Zealand, and Ireland in the liberal market economy group and Germany, Japan, Switzerland, the Netherlands, Belgium, Sweden, Norway, Denmark, Finland, and Austria in the group of coordinated market economies. Their classification scheme left five additional European countries (France, Italy, Spain, Portugal, Greece, and Turkey) in a mixed group, which, Hall and Soskice (2001a) argued, had specific capacity for non-market coordination concerning corporate finance but had more liberal arrangements concerning labor relations. Hall and Gingerich (2009) later developed a two-factor model to account for national variation in institutional structure: one for coordination in corporate governance (shareholder power, dispersion of control, and size of total stock market valuation as a percentage of GDP), and the other for labor relations (extent of wage coordination, degree of wage co- 
ordination, and the rate of labor turnover). They reported a moderately high correlation (0.74) between their measure of labor relations and a measure of training systems based on the proportion of upper secondary students in vocational or technical training programs and the country mean scores on a literacy test for 20-25 year olds who left school before completing secondary education. A scatterplot of countries on axes for their measure of labor relations and corporate governance showed a rough clustering of countries: the liberal market economies having low coordination in corporate governance and in labor relations and the coordinated market economics and what they called the "mixed market economics" (France, Italy, Portugal and Spain) having values on these two dimensions that were higher than those for the liberal market economies. 3

Other researchers in the VoC tradition questioned, elaborated, or modified this scheme. Busemeyer and Trampusch (2011) (see also Busemeyer 2009 and Thelen 2007) used the degree of firm involvement and the strength of VET to argue for five types of training regimes: (1) the collective, which included Germany, Austria, Switzerland, the Netherlands, and Denmark, (2) the statist, the core of which includes France and Sweden, which relied on direct state involvement in the provision of vocational skills via state-run or funded vocational schools with marginal employer involvement, (3) the liberal, which relied on narrow on-the-job training, (4) the "segmentalist" solution of self-regulation, which they argued describes the case of Japan, and (5) a southern European group (including Italy, Greece, Portugal, and Spain) which have below average levels of both public and private spending on education, below average shares of the working-age population with at least an upper-secondary education, low employer and also low public commitment to VET and very high levels of youth unemployment.

The CASMIN study organized by Shavit and Müller produced a one-dimensional classification of the countries they studied based on the strength of the effect of educational attainment on occupational status. Their classification put Switzerland, Germany, and the Netherlands at the top, followed by Australia, Italy, Sweden, Israel, Taiwan, and France, with the United States, Japan, and the United Kingdom at the bottom (Müller and Shavit 1998). This ranking is actually quite similar to that obtained from their scoring of vocational specificity for secondary education (the proportion of secondary school graduates who enter the labor force with occupationally-specific skills). They then performed a re-

\footnotetext{
${ }^{3}$ Kenworthy (2006) similarly built on Hicks and Kenworthy (1998) to propose a single-dimensional "cooperation" index.

${ }^{4}$ They ranked Germany, the Netherlands, and Switzerland, as countries where a large proportion of secondary-educated workers graduate with occupationally-specific skills, Australia, the UK, France, Israel, Italy, Sweden, and Taiwan as having a moderate proportion, and Ireland, Japan, and the U.S. having very few secondary school graduates with occupationally specific skills.
} 
gression of their occupation-education association measure on their four country-level education variables, and found that vocational specificity had the strongest effect.

Even though the CASMIN project explicitly incorporated tertiary education into their institutional analysis, it did not figure as strongly in their classification as did the vocational specificity of secondary education. However, the growing importance of tertiary education has demanded attention and in the process added complexity to the $\mathrm{VoC}$ and CASMIN schemes. In analyzing different "modes of differentiation" Arum, Gamoran, and Shavit (2007) identified only Italy and the Czech Republic as still (given other historical changes) having "unified" systems. Binary systems, which focus more strictly on vocational education in the second tier tertiary institutions, are present in countries like Germany, Austria, and Switzerland that have strong secondary-level "qualificational space" systems. Arum, Gamoran, and Shavit (2007) further noted that even liberal market countries like the U.S. have to some extent reoriented their lower-tier tertiary programs in a vocational direction. They argued that the UK and Australia - two other liberal market countries - upgraded their vocational systems to give them academic status and transform their tertiary systems from binary systems to ones that were formally unified, though in practice they saw the systems of these countries as distinct from those of Italy and the Czech Republic. They classified the UK, France, Germany, the Netherlands, Russia, and Switzerland as binary, and they classified Israel, Japan, Korea, Sweden, Taiwan, and the United States as "diversified" systems, meaning that the second tier consists both of occupationally oriented programs and also programs that potentially lead to academic education via transfer or continuation at upper-tertiary institutions. One sees echoes of the CASMIN and VoC classifications in Arum, Gamoran, and Shavit (2007); countries with vocationally specific secondary systems are seen as having binary tertiary systems, though the classification of the UK, France, and Sweden is inconsistent across the various schemes.

\footnotetext{
${ }^{5}$ The inconsistency of classifications at the tertiary and the secondary level could reflect a real institutional divide between the secondary and tertiary tiers at least in some countries. However, other countries also receive ambiguous or conflicting treatment of their training regimes even when the focus is exclusively on one level of education or the other. Thelen (2001), for example, saw Italy as a coordinated market economy in contrast to Hall and Soskice (2001a). As another example, the Dutch system is said to combine elements of liberal and coordinated market economies and rely more heavily on general, school-based training compared with other nations that have coordinated economies (Busemeyer and Trampusch 2011; Anderson and Nijhuis 2011). Busemeyer (2014) ended up reclassifying the Netherlands into his mixed group of countries because its VET system is largely school based, which, in this sense, is similar to the systems of Belgium and France. School-based systems are also of considerable importance in the French part of Switzerland and in Denmark (Busemeyer and Trampusch 2011). Switzerland more generally is seen as having moved its educational system towards greater provision of general skills (Culpepper 2007; see also Gonon and Maurer 2011). Meanwhile, both Austria and Switzerland have responded to the increased attractiveness of higher education by introducing double-qualification certificates in vocational programs that facilitate movement into higher education by these graduates to a greater extent than in Germany
} 
Educational systems can also affect labor market outcomes through regulatory features that strengthen or loosen the connection between specific educational credentials and specific labor market outcomes. Occupational licensing and, to a lesser extent, certification, are important forms of occupational closure that generally raise wages while (several studies argue) having a negative effect on employment (Weeden 2002; Bol and Weeden 2015; Kleiner 2006; Redbird 2017). The proportion of jobs covered by a license has varied both over time and across countries. For example, the number of workers covered by licensing regulations increased in the U.S. from 5\% in the 1950's to $18 \%$ in the 1980 s and was associated with a wage increase of $15 \%$ in American data - about the same size as the effect of unions (Kleiner and Krueger 2013; Kleiner 2016). Twenty two percent of workers in the European Union are in licensed occupations (Koumenta and Pagliero 2017). Koumenta and Pagliero (2017) further found that licensing is associated with a $4 \%$ wage increase across the EU, and that licensing reduces the number of people employed in the affected occupation, in particular for foreign born workers.

Because licensing requirements often include specific educational credentials, it would seem that countries with a high proportion of jobs that require licensing would have the tight connection between educational programs and occupational placement that is thought to characterize coordinated market economics. Is the ranking of these countries according to the proportion of jobs that are licensed strongly associated with the country clusters identified in the VoC or the CASMIN projects? The answer is "it depends on the country." Germany, the Netherlands, and Austria rank in the top eight EU countries out of the 28 that are included in the study by Koumenta and Pagliero (2017). However, Denmark, which is also included in the group of collective skill formation countries by Busemeyer (2014), ranks last of the 28 countries in the proportion of its workers who are licensed. Moreover, Belgium, Finland, and Sweden, which are included in the CME group by Hall and Soskice, are all ranked in the bottom six of the 28 countries in terms of the proportion of their workers who are licensed. If we elaborate the criterion to count both certified and licensed workers, the ranking of countries changes hardly at all. Meanwhile, the UK, which is the most iconic liberal market economy in the EU data, is ranked pretty much in the middle of the list (15 of 28). As with the other work discussed here, we see a nowfamiliar pattern: Germany and to a lesser extent Austria emphasize vocational training

(Nikolai and Ebner 2011). Looking at the connection between school and work from a labor market point of view, Thelen (2012) highlights the Netherlands, Denmark, and Sweden for their "flexicurity" policies, which are intended to increase labor market flexibility in the direction of a liberal market economy while maintaining the social insurance system characteristic of a social democratic country. These institutional details are arguably quite important, yet they work against the creation of clear groupings or scoring of countries on how national institutions shape skill formation systems and their link to the labor market. 
and have large proportions of their workers who are in licensed occupations. However, the clustering or ranking of other European countries can be quite variable from one scheme to another.

One-third of all jobs in OECD countries are now either temporary, part-time, or in self-employment (Organisation for Economic Co-operation and Development and Organisation for Economic Co-operation and Development 2015). Because the strength of pathways from school to work may differ for permanent vs temporary jobs and for full-time vs part-time jobs, the growing rise in these forms of employment (Kalleberg 2011) is of potential importance in comparing the structure and consequences of educational pathways across countries. Precarious jobs are typically conceptualized on multiple dimensions, i.e., whether a job is temporary/insecure, low-wage, part-time, lacking fringe benefits, or not providing a pathway to better jobs in the future as key attributes (Kalleberg 2011; Broughton et al. 2016). Not all of these conditions necessarily have the same relationship with precariousness in all countries (Kalleberg 2011): Greece, Spain, and Italy, for example, have high rates of involuntary part-time work (Broughton et al. 2016), while the Netherlands has relatively high rates of voluntary part-time (Verbakel and DiPrete 2008) as well as marginal part-time work (Broughton et al. 2016). Fixed term contracts - especially for young workers - are relatively high in France, Spain, and Portugal and, increasingly, the Netherlands (de Graaf-Zijl, Van den Berg, and Heyma 2011). These differences might also matter for cross-country comparison because countries differ in the extent to which their labor market makes use of part-time and contingent workers. Despite the growing literature on precarious work, the extent to which country differences in the distribution of workers across types of employment relationships affects the strength and consequences of educational pathways is largely unexamined.

In summary, several literatures imply variation across countries in the coherence of pathways between educational outcomes and labor market placement, and they also imply that institutional arrangements should have implications for labor market outcomes including particularly wages and employment. In practice, however, there is strong consensus only on the relative position of a few countries that are asserted to be ideal-typical in their institutional arrangements. Meanwhile, this literature lacks a clear assessment of how country differences in skill formation systems at the upper secondary level map onto country differences in skill formation at the tertiary level. Finally, it lacks a clear test of the relationship between institutional arrangements and labor market outcomes. We provide such a test below. 


\section{Analytical Approach}

The linkage approach provides a way of measuring linkage strength both at the national level and at the level of specific pathways. It provides a metric for establishing whether country differences in linkage strength from secondary and lower-tertiary outcomes are similar to or different from country differences at the upper-tertiary level. It provides a strategy for assessing whether pathway structure matters for educational outcomes. Finally, it provides a way of assessing whether institutional differences matter for outcomes in the "global" nation-level sense that is typically argued in these literatures. Indeed, by focusing attention on pathways within nations, the linkage approach also interrogates the institutional literature concerning the mechanisms by which national institutions - what we could call "macro-structure" - affects outcomes.

The linkage approach calls attention to three distinct levels at which skill formation systems can affect outcomes. At the individual level, a skill formation system can affect outcomes through the particular skills it imparts to a worker. At the pathway level, it affects outcomes in several ways: by shaping the value (and maybe also the content) of skills via the quality of alignment between educational credentials and occupations, by affecting the probability that a worker ends up working in a job or occupation that is well matched to her skill set, and by affecting the consequences of working in one or another occupation after having been educated or trained in a particular field of study. These quantities depend not only on the content of educational and training programs but also on quality of communication of occupational options to students, on signaling mechanisms that make skills more visible and comprehensible to potential employers, on control of the rate of entry into education and training programs, or on customs or regulations that restrict hiring to workers that have specific credentials.

The third level at which skill formation systems can affect outcomes is the level of macro-structure, i.e., the national environment. In general, there are three distinct causal paths between macro-structure and outcomes, which are not always well differentiated in the literature. One mechanism concerns the impact of macro-structure on the strength of individual pathways linking educational credentials and the occupational structure. The second mechanism concerns the distribution of workers across educational credentials and across occupations, both of which can differ considerably across countries. The third mechanism concerns the extent to which pathway effects are influenced by the macrostructure of a country.

The existing literature on skill formation systems has not always clearly differentiated between the impact of macro-structure on the marginal distributions and the impact of 
macro-structure on the coherence of the pathways linking educational and occupational positions as measured by the structure of association between education and occupation, net of the marginal distributions. This distinction can be very important in making sense of country differences and of changes in skill formation systems over time, as Elbers, Bol, and DiPrete (2021) showed in their analysis of differences over 40 years in the French and German skill formation systems.

Macro-structure may also play an important role in shaping the consequences of pathway strength for labor market outcomes. As discussed in Bol et al. (2019), workers with a particular educational credential may work in an occupation that is well matched to their educational credentials in terms of skills and institutional closure mechanisms. Or they may work in an occupation that is less well matched. An existing literature generally finds that works who are well matched gain a labor market advantage (Witte and Kalleberg 1995; Werfhorst 2002; Wolbers 2003; Roksa and Levey 2010). The coherence of educational pathways will generally affect how likely a worker is to match well; more coherent pathways produce a higher proportion of matches, while less coherent ones yield a higher proportion of workers who are not well matched. But what determines the size of the advantage from matching? The macro characteristics of a skill formation system may play a role here. If the pathways between educational credentials and occupations are generally highly coherent, one would expect less well matched workers to have a harder time in the labor market; closure mechanisms in such labor markets would make it harder to do well against workers who are well matched. These effects occur as a consequence not only of the pathway strength for one's own credential but also as a consequence of the coherence of other pathways leading to the occupations that may be mismatches for someone holding the focal educational credential. Because of this, one would expect the macro-structure to matter for the size of these pay gaps. The extent of this effect, moreover, should depend on the extent to which countries with more structured skill formation systems have uniformly stronger pathways as well. A more uneven relationship between the individual pathways of a country would weaken these country-level effects.

We employ a multi-group segregation approach to study the strength of linkage between educational and occupational outcomes introduced by DiPrete et al. (2017), which builds on entropy based measures of multi-group segregation and in particular, the Mutual Information Index, $M$, and the closely related entropy-standardized measure, $H$ (Theil and Finizza 1971; Theil 1972; Reardon and Firebaugh 2002; Mora and Ruiz-Castillo 2011; Elbers 2021). This approach offers considerable advantages over other comparative studies that characterize skill formation systems in terms of a limited set of country-level attributes such as Hanushek et al. (2017). 
Details of the approach can be found in DiPrete et al. (2017) and Bol et al. (2019). Here we provide a summary of the most important points. Let $G$ be the set of combinations of educational levels and fields of study (i.e., the level-fields, which we heuristically refer to as educational "credentials" and below refer to as "broad level-fields" because they are at the level of detail that is common across the countries under analysis). Let $J$ be the set of occupational outcomes (using a standardized coding that is common across countries). These together form a $G \mathrm{x} J$ contingency table that can be constructed for each country or combination of countries using the micro-level data along with appropriate probability weights. The probability of being in level-field $g$ and occupation $j$ is $p_{j g}$, where $\sum_{j} \sum_{g} p_{j g}=1$. The conditional probability of being in occupation $j$, given level-field $g$, is represented as $p_{j \mid g}$. The marginal probabilities $p_{\cdot g}=\sum_{j} p_{j g}$ and $p_{j} .=\sum_{g} p_{j g}$ describe the univariate level-field and occupational distributions, respectively. We define $M(G ; J)$ as "total linkage," which measures the dependency between the level-fields and occupations contained within $G$ and $J$. Linkage is high for a specific level-field when the occupational distribution of workers with that level-field deviates strongly from the overall occupational distribution. We call this the "local linkage" $L$ of level-field $g$, and define it as

$$
L_{g}=\sum_{j} p_{j \mid g} \ln \frac{p_{j \mid g}}{p_{\cdot j}}=\sum_{j} p_{j \mid g} \ln \frac{p_{j g}}{p_{g \cdot p_{\cdot j}}} .
$$

The total linkage, $M$, can then be defined simply as the weighted average of the local linkage scores for all level-fields in $G$ or, equivalently, as the weighted average of the local linkage scores for all occupations in $J$ :

$$
M(G ; J)=\sum_{g} p_{g} \cdot L_{g}=\sum_{j} p_{\cdot j} L_{j} .
$$

As can be seen in Equations 1 and 2, both the local linkage scores of a country and the total linkage strength of a country depend on the structure of association (i.e., the relational structure) between educational outcomes and occupations as well as on the marginal distributions of educational and occupational outcomes. Differences in the total linkage strength of countries, or of the same country over time, can be expressed in terms of differences in the local linkage scores for each of the level-fields. These differences, therefore, depend both on differences in the structure of association and differences in the marginal distributions (Elbers 2021).

A partial standardization of the $M$ is obtained by dividing $M$ by the entropy of the educational distribution to obtain the $H$. This standardization, however, does not adjust for the influence of the occupational marginal distribution on $M$. To adjust for the influ- 
ence of both marginal distributions, we decompose country differences in linkage structure into components generated by differences in the marginal distribution of level-fields, differences in the marginal distribution of occupations, and differences in the local linkage scores attributable to the structure of association between educational and occupational outcomes (Elbers 2021). The decomposition is accomplished through the use of iterative proportional fitting (IPF) algorithms that produce contingency tables whose marginals match those of a target table while maintaining the same pattern of association as found in the source table. In this paper, we use as target marginal distributions the distributions obtained by combining the data for all the countries in this study into a single supercountry, where the weights for each country are scaled so that large countries contribute proportionally more than small countries to the super-country marginal distributions.

We estimate fixed effects regressions in which the outcome is either relative earnings (described below) or employment, conditional on being in the labor force. The analyses estimate the effect of local linkage strength of the respondent's combination of educational level and field of study on labor market outcomes, both as main effect and in interaction with occupational match quality. To make the country differences in local linkage strength as comparable as possible, we use measures of local linkage strength from tables that are adjusted to have the same educational and occupational marginal distributions. The core model is

$$
y_{i}=\alpha+\beta_{1} L_{i g m}+\beta_{2} Q_{i g j}+\beta_{3} L_{i g m} Q_{i g j}+\delta X_{i}+F_{i g}+S_{i k}+C_{i m}+\varepsilon_{i}
$$

where $i$ indicates individuals, $g$ indicates broad level-field (the category scheme used across all countries), $k$ indicates detailed educational level (minor differences between major levels that may not exist in all countries), $j$ indicates occupation, and $m$ indicates country. Using this notation, $F_{i g}$ is a fixed effect for $i^{\prime} s$ broad level-field combination $g$ using ISCED-97 educational fields and the broad educational level coding described in the preceding section, $L_{i g m}$ is the linkage score for the educational level-field g in country $m, Q_{i g j}$ is the quality of the match between the broad level-field and the occupation for individual $i$ in broad level-field $g$ in occupation $j, S_{i k}$ is a fixed effect for detailed education type $k$ within educational level, $C_{i m}$ is a fixed effect for $i^{\prime} s$ country $m$, and $X_{i}$ are individual characteristics (gender, age, employment relationship) for individual $i$. 6 When terms involving match quality are omitted from the model, $\beta_{1}$ gives an estimate of the total effects of local

\footnotetext{
${ }^{6} \mathrm{Bol}$ et al. (2019) performed supplementary analyses with data from the Programme for the International Assessment of Adult Competences (PIAAC), which contain a measure of cognitive skill, and found that the inclusion of a cognitive skill variable did not materially change the coefficients of local linkage and occupational matching on wage outcomes.
} 
linkage strength, net of other terms in the model. When match quality is included, the effect of $L$ on $y$ runs through the effect of $L$ on $Q$ as well as the impact of $L$ on $y$ separately for those who are well-matched and those who are less-well matched (or via a continuous measure of $Q$ if a continuous measure is used).

We use both a threshold measure and an underlying continuous measure developed in Bol et al. (2019) to assess match quality. First, we identify the 10 largest occupational destinations for each level-field. Within this set, we compare the number of occupational incumbents with the number that would be expected if field of study were unrelated to occupational incumbency, conditional on educational level, and rank them. To obtain a binary measure, we take the two occupations that rank highest, and then as a robustness check, we also take the top three occupations. We call them the "matched" occupations. We further harmonized the results by using the same definition of matched occupations across all countries. The list of the top two matched occupations for each of the 25 educational categories can be found in Appendix Table A.2. Note that our operationalization of matching occupations is not gender specific. We do this for the reason that we are interested in education-specific pathways and want to see how women and men fare in terms of the same set of statistically matched occupations. However, we also discuss the implications of using gender-specific occupational matches in section 4.5 below.

From a substantive perspective, the use of a large number of countries in the analysis has four important advantages. First, we can better evaluate how variation in local linkage strength for the same educational pathway across countries is associated with labor market outcomes. Second, we can better evaluate how the effects of local linkage strength vary with the quality of the occupational match. Third, we can evaluate the consistency of the country clusters derived in the CASMIN and VoC literatures - and as modified with data on the prevalence of occupational licensing in the country - with empirical measures of total linkage strength computed from the EU LFS data. Fourth, we can determine whether the effects of local linkage strength and the quality of occupational matches differ for highlinkage and low-linkage countries. We address these questions in the following sections.

\section{Data Description}

The data for our analysis come from the European Union Labor Force Survey (EU LFS). The EU LFS is a large household survey that provides labor force information for people aged 15 or older for all member states of the European Union along with Norway, Iceland, Switzerland, and the United Kingdom. These data are collected by the participating countries and then processed by Eurostat. The EU LFS was significantly restructured in 2006 
to be administered as an annual survey. We analyze five waves of these data, i.e., data collected between 2006 and 2010 as a group because these years use consistent coding of educational and occupational information.

The 2006-2010 EU LFS waves provide information about a respondent's education using ISCED97 educational levels and fields of study (UNESCO 2006). This scheme distinguishes primary (level 1), lower-secondary (level 2), upper secondary (levels 3a, 3b, and 3c), post-secondary/non-tertiary (levels 4a, 4b, and 4c, which are described as postsecondary education that prepares a student to enter tertiary education), first stage of tertiary education distinguishing short- or medium-term programs (level 5b, "lower tertiary") from long-term programs (level 5a), and second stage tertiary leading to an advanced research qualification (level 6). Countries in the EU do not necessarily have all of these levels; some countries like Spain, Croatia, or the United Kingdom do not have field differentiation at level 4, or, like Ireland, do not have field differentiation at level 3. Many countries do not have field differentiation at level 2, and so we limited our analysis to workers who had at least an upper-secondary level of education (i.e., level 3).

In order to achieve a harmonization over twenty or more countries, some simplification of the ISCED97 codes in the EU LFS was necessary. We collapse sub-levels within the same educational level (e.g., 3A, 3B, 3C within level 3, which is upper secondary in the ISCED system). As in Bol et al. (2019), we collapse level 4 with level 3 as two levels described by the ISCED as "non tertiary." We also collapse levels 5a and level 6 together to produce an "upper-tertiary" level. Two countries in our sample - Italy and Hungary lack a developed set of fields of study at the lower-tertiary level but do have differentiated fields of study at level 4 as well as at level 3. In order to keep these two countries in the analysis, we treat their level 4 fields as if they were at level 5b. As noted above, we refer to this harmonized coding below as the "broad level-field." We refer to the more detailed educational level coding in the ISCED-97 classification as the "detailed educational level."

The EU LFS documents sixteen fields of study in the codebook (some countries have more detail than that in their data). In order to compare many countries and at the same time avoid sparseness bias (discussed below), we analyzed data in terms of the eight major field of study groups that these sometimes more specific fields are nested within. To be specific, the humanities, languages, and arts group includes those in foreign languages,

\footnotetext{
${ }^{7}$ In the 2006 to 2010 datasets, educational levels and fields of study are coded in the ISCED 1997 scheme, and occupations are coded using ISCO-88. Countries can choose the level of detail they report on the ISCO-88 scheme, ranging from 1 to 4 digits. This study includes countries that report at least 3 digits. Since 2010, there have been changes to the educational and occupational coding schemes. In 2011, the EU LFS switched to ISCO-08. In 2014, the educational coding scheme was changed to ISCED 2011, and in 2016 the educational coding scheme was changed to ISCED-F 2013.
} 
and the science, mathematics and computing group includes those in life sciences, physical science, mathematics and statistics, computer science and computer use. When taken together, our harmonized schedule involves three educational levels (non-tertiary, lowertertiary, and upper-tertiary), each with eight fields of study. The full set of educational categories is shown in Table B.1. As noted above, we sometimes refer to these educational categories as educational "credentials," but it is important to keep in mind the distinction between the type of harmonized categories available to study in the EU LFS and the specific educational credentials that students actually earn in their national educational systems, which for some countries could number in the hundreds. Both because of qualitative differences in the educational systems across countries and because of data limitations, it is not possible to perform a comparative study of pathway structure using each country's native educational level and field of study categories. While we would expect results to differ if detailed native categories and datasets of sufficient size were available, we note that in a comparison of results between France and Germany where it was possible to use both detailed native categories and harmonized, more parsimonious educational categories, DiPrete et al. (2017) found that the major country differences were preserved.

As reported elsewhere (DiPrete et al. 2017), the analysis of tables with too few cases in a level-field combination inflates the apparent linkage strength. Bol et al. (2019) found that sparseness bias in practice is not a problem when there are at least 50 cases in a levelfield combination, and other checks with the EU LFS data have found robust results even when using a 30-case threshold so long as the number of categories with relatively few cases is small as is true here. We used the 30 case threshold in these analyses in order to retain the full set of pathways for all included countries though the vast majority of pathways in this study have a least 100 cases per country. 8 We then use the local linkage scores generated from these samples in the analyses described below. The EU LFS contains data for thirty-one countries. We compute linkage scores between educational and occupational outcomes using harmonized three digit ISCO-88 codes, which are provided in the EU LFS data along with probability weights contained in the EU LFS.9 We exclude Malta, Bulgaria, Poland and Slovenia because they lack three digit ISCO-88 codes. Cyprus, Denmark, the Slovak Republic, Norway, and Iceland have some educational categories with sample sizes below our size threshold and therefore they are excluded from our analysis. This leaves us with 22 of the 31 countries as suitable for analysis of the pathway

\footnotetext{
${ }^{8}$ Of the 550 pathways in our study (22 countries times 25 categories), $99.6 \%$ have 50 or more cases and $98.4 \%$ have 100 or more cases.

${ }^{9}$ Some of the cases in the EU LFS from the German and French samples have zero weights. Eurostat advised us certain respondents from these two countries were not used in the weighting process and were assigned a zero weight. These cases were excluded from the analyses reported below.
} 
structure between educational and occupational outcomes. Sweden is then dropped from the earnings analysis because earnings information is not available for Sweden in the EU LFS.

In addition to the eight harmonized fields of study mentioned above, the EU LFS includes a code for general education. More than $10 \%$ of the workers in our sample have a general education non-tertiary degree in Estonia, Ireland, Lithuania, Latvia, and Spain. In contrast, fewer than 5\% are in this category in Germany, the Czech Republic, France, Croatia, Italy, Luxembourg, the Netherlands, Portugal, and the United Kingdom. We expect linkage in the non-tertiary general education category to be low and therefore differences among countries in linkage strength will partly depend on the proportion of workers who are in general education categories as well as on the strength of local linkage between specific level-fields and the occupational structure. We analyze the data with this category alternately included and excluded in order to distinguish its impact from the impact of linkage strength for specific level-field categories. The proportion of the samples in these categories with a general education field at the lower- or upper-tertiary level is extremely small in all the countries in our study. 10 We therefore limit our analysis of the tertiary level to workers who have a specific field of study code.

The dependent variable for the earnings analysis is the monthly take-home pay from the main job (i.e., net earnings), measured in deciles for the last monthly pay received before the reference week. Relative earnings correspond at the country-level to a positional measure of inequality; they abstract away from the extent to which rates of return to education differ by country because of country differences in earnings inequality as measured, for example, by the Gini coefficient. While rankings based on take-home pay can deviate from rankings based on gross earnings, other research finds the two sets of rankings to be broadly similar across European countries (Figari and Verbist 2014). This variable is only available for wage and salary workers, so self-employed workers are excluded from the earnings analyses below. Data on take home pay is available only for 2009 (when it became an obligatory item for the EU LFS) and 2010 in our five-year window. Because earnings are measured on a within-country relative scale, we cannot automatically translate these values into absolute measures of earnings. This is not a major disadvantage, however, because differences in exchange rates and in purchasing power make such translations problematic even when nominal earnings are available. Eurostat reports that the earnings variable is not fully comparable across countries because it is collected in different ways in different countries (Eurostat 2012). The use of fixed effects for countries will alleviate this

\footnotetext{
${ }^{10}$ The median percentage of people with lower-tertiary, general education degrees is $0.017 \%$, and the median percentage of people with upper-tertiary, general education degrees is $0.025 \%$.
} 
problem somewhat, but it is inevitable that there will be comparability problems when analyzing so many countries at once. We use the greater precision possible from five years of data to calculate the local linkage scores and we limit our analysis of earnings to 2009 and 2010 .

Our main focus is on adults who are between 18 and 70 years old and who are coded as employed or (for the unemployment analysis) unemployed, i.e, not inactive or in compulsory military service and who have not been students in the four weeks before the interview.11 The EU LFS reports whether a worker is employed or unemployed and, if employed, whether the worker has an indefinite term job or a fixed-term job. It also reports the full-time or part-time status of the main job, the number of hours per week usually worked per week, total duration of the temporary job or work contract of limited duration, whether the respondent has more than one job, and labor force status one year ago. We used the usual hours per week variable to measure whether or not the job was full-time (which we here operationalized as 32 hours, reflecting the fact that there is no strict definition of full-time work in the EU, with variably 30-35 hours or more being considered "full-time.").12 Countries differ in the proportion of workers who are in part-time and/or temporary jobs. We address below the question of how strongly these statuses are related to local linkage strength and whether the effects of linkage strength and matching on labor market outcomes are affected by the type of employment relationship a worker has.

Appendix Table A.1 shows the sample size for each country for the earnings analysis as well as the distribution by employment status, employment relationship, age group, gender, and general education across the five years that we study here, along with the country abbreviations that are used in the tables in this paper. We note that that there is considerable variation across these countries on a variety of measures, including their gender composition, the age distribution, and the proportion of workers who are either parttime or in temporary jobs. We note again that the sample counts for the earnings analysis use only data from 2009 and 2010. The local linkage scores are computed with data from all five years from a total unweighted sample of over 4 million cases.

We present our results in the sections below. First, we compare the total linkage strength of countries. We then calculate the ranking of countries using data that are adjusted to have the same educational and occupational distribution in order to distinguish the effects of country differences in marginal distributions from country differences in the strength of association between educational credentials and occupations. We address whether coun-

\footnotetext{
${ }^{11}$ Among those who are over $65,2.3 \%$ are employed and $0.26 \%$ are unemployed.

${ }^{12}$ We used the "usual" hours rather than the "actual" hours because actual hours only refers to the reference week, which is not in the window of work time that produced the last pay check.
} 
try differences are stronger at lower levels of education, where there is recognized variation in VET systems, than they are at upper-tertiary levels, where professional licensing may create more internationally standardized institutional practices. We also examine the extent to which variation in local linkage strength can be explained in terms of variation in non-standard employment across countries. Then we examine the extent to which alternative methods of grouping countries by their linkage structure produce consistent results that conform to the clusters and rankings proposed in the skill formation, VoC, and occupational licensing literatures. Finally, we estimate the impact of local linkage strength, the quality of the match between educational credential and occupation, and the macrostructure of linkage on earnings and employment outcomes. In assessing the impacts of local linkage strength and the quality of occupational matches, we use multiple indicators of match quality, and we examine whether using gender-common or gender-specific matching has an impact on the results. With this modeling strategy, we examine the extent to which macro-structure affects stratification outcomes primarily through its impact on local linkage strength, or whether the macro-structure of a country's skill formation system affects outcomes over and above the effects of pathway structure.

\section{Results}

\subsection{How Do Countries Differ in their Total Linkage Strength?}

We computed the total linkage strength $(M)$ for 22 countries in the EU LFS from the contingency table of education by occupation from the unadjusted data and then also the contingency table we obtain after adjusting both the educational and the occupational distributions of countries using IPF to have the same value as in the table obtained by combining the weighted data for all 22 countries. We present their values (including error bars) in Figure 1, where the left panel includes workers who have non-tertiary general education and the right panel excludes the non-tertiary general education workers. Countries differ considerably in the size of their unadjusted $M$. The Netherlands, Italy, Latvia, and Estonia all have unadjusted $M$ indices below 0.75. At the other extreme, Luxembourg has an unadjusted $M$ that is greater than 1.0, and Croatia and Greece similarly have an $M$ greater than 1.0 after their margins are adjusted to match those of the 22 countries taken in the aggregate. The results presented here use the entire samples as described above. We address in section 4.2 below the extent to which these results are stable if we focus on specific age groups or educational levels.

Figure 1 shows that the difference between the gray and brown bars is notable for 
some countries. As a consequence, the rankings of total linkage strength differ depending on whether the unadjusted or adjusted data are used. These shifts demonstrate that differences in the total linkage strength of countries depend both on country differences in the education and occupation marginal distributions and on country differences in the strength of association between particular educational credentials and particular sets of occupations. 13 Countries that have higher $M$ when the unadjusted data are used have workforces that are shifted towards educational and occupational categories that link together relatively tightly: Germany, Finland, and Sweden are examples of such countries. Other countries have relatively low total linkage strength because a higher proportion of their workers earned educational credentials and work in occupations that link together relatively weakly; Ireland, Romania, and the Czech Republic are examples. This variation in marginal distributions is a potentially important component of the explanation for country differences in total linkage strength in the unadjusted data. 14

Another regularity visible in Figure 1 is that total linkage strength is higher when the general-education non-tertiary workers are excluded from the calculation because - not surprisingly - the general-education non-tertiary pathway has weak local linkage with occupations. Greece, for example, has an unadjusted total linkage strength over 1.2 if general education non-tertiary workers are excluded. However, because Greece has a fairly high proportion of workers with at least a secondary degree who have a general education credential (see Figure A.1), its total unadjusted linkage score drops to 0.98 when these workers are included. Croatia, Luxembourg, and Finland, in contrast, have relatively low proportions of their workforce with general-education non-tertiary workers, and so their unadjusted total linkage is not as much affected when the non-tertiary general-education workers are removed. Overall, the impact of the general-education non-tertiary workers on the ranking of a country is not huge: if we divide the countries into the top half and the

\footnotetext{
${ }^{13}$ The shift depends on the particular marginal distributions of educational and occupational categories that are used as the standard in the IPF adjustment. Countries that have small shifts may (though not necessarily do) have marginal distributions that are closer to the overall distribution across the twenty-two countries.

${ }^{14}$ For example: the difference in linkage strength between Germany and France is driven both by differences in the structure of association and by differences in the marginal distributions of workers across educational and occupational categories. To take a different example, the Netherlands has relatively low linkage strength, and the reason for the low ranking is structural; the Netherlands ranks 15th on the unadjusted $M$ when general-education workers are included and 19th when they are excluded. It ranks even lower (22nd) after adjusting the marginal distributions to be the same in all countries, and this low ranking is unaffected by including or excluding the workers with a non-tertiary general education (cf. Rözer and van de Werfhorst 2020). At the same time, - and to make another specific substantive comparisonthe gap in adjusted $M$ scores for the Netherlands and Germany is smaller than is the gap for the unadjusted $M$ scores. In other words, the gap between Germany and the Netherlands is partly compositional even as the major portion of the gap is structural.
} 
bottom half of the rankings, we note that the clusters obtained from the $M$ computed on adjusted marginals are the same regardless of whether the general-education non-tertiary workers are included or not.

Figure 1: Total Linkage Strength (M) Unadjusted and Margins-Adjusted Data, by Country
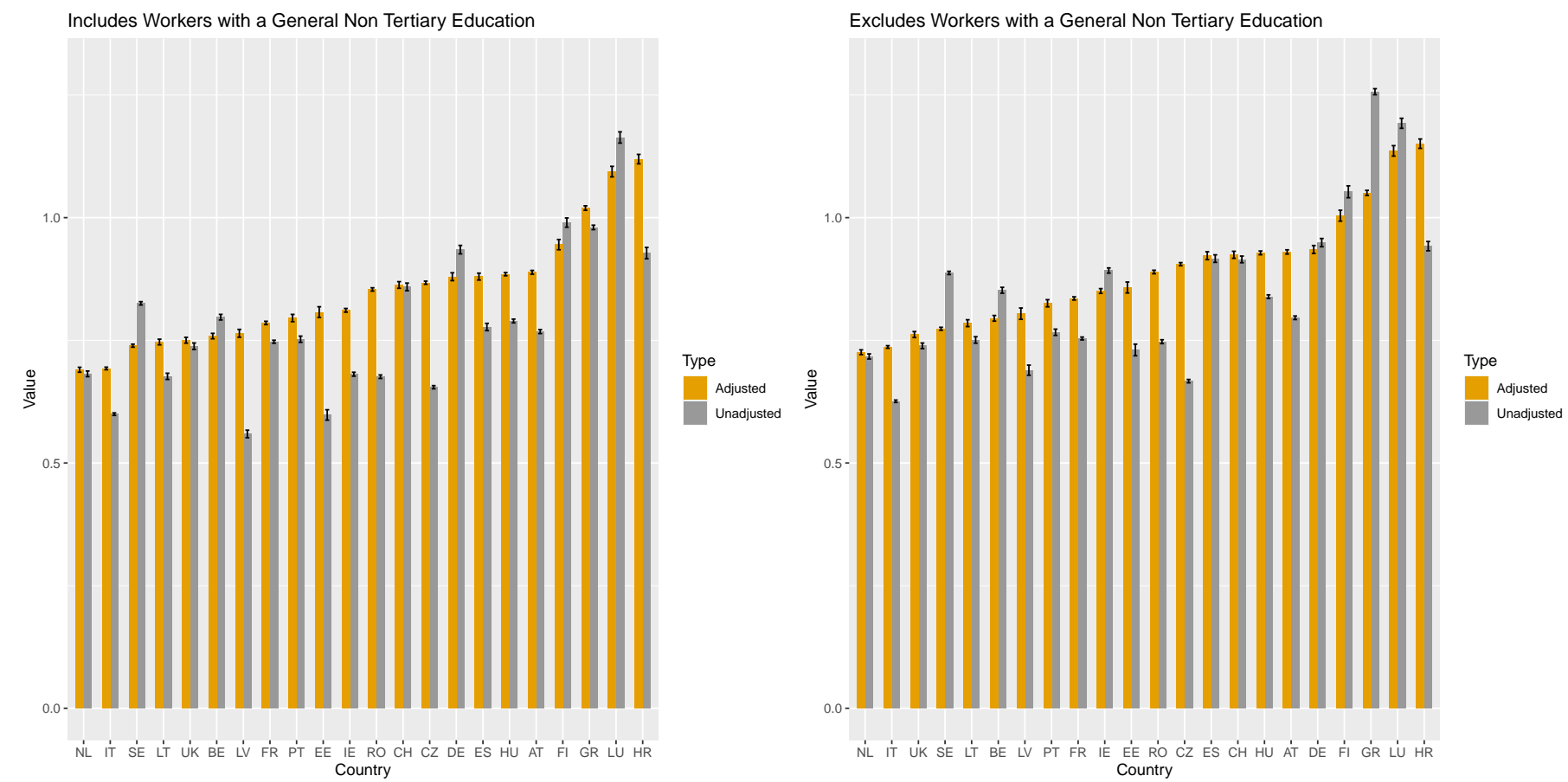

\subsection{Internal Heterogeneity of Linkage Strength by Levels and Fields}

The variation in total linkage strength by country raises the question whether the pattern of country-level variation observable in the complete data is similar to that found at different levels of education or across different fields of study within the same level. It would not be surprising to find that pathway structure for certain credentials (e.g., engineering or medicine) is relatively similar across countries while other credentials - for example those involving what is often referred to as vocational education - differ more substantially in line with the institutional theories discussed earlier. We address these questions in more detail in Appendix B. As can be seen in Table B.1, local linkage strength is higher at the tertiary level than it is at the non-tertiary level. At the non-tertiary level, local linkage strength is especially low among those workers who report having a general education. For 
all educational levels, the extent of country-level variation is considerable. However, when one looks at specific fields - in particular, the health fields, one sees relatively uniform professionalization of the health fields at the upper-tertiary level. Given the strong emphasis on vocational education in the comparative literature, it would not be surprising if country variation at the non-tertiary level was greater than at the tertiary level, but in fact, country variation at the tertiary level is nearly as large as it is at the non-tertiary level (for three of the eight fields, the coefficient of variation in the unadjusted data is larger at the upper-tertiary than at the non-tertiary level). As the right-most column of Table B.1 shows, some of this variation is explained by differences in the occupational distribution across the countries. 15 There is clearly less variation across countries in upper-tertiary linkage than in non-tertiary or lower-tertiary linkage once country differences in the educational and occupational marginal distributions are taken into account.

Underlying this question is the more general question of the internal heterogeneity of pathway strength as a function of total linkage strength. We ranked the local linkage strength of each of the 25 educational credentials across the 22 countries (with the top ranked country for each credential scored as 22 and the bottom ranked country scored as one) and we compared the within-country distribution of these rankings as a function of the ranking of that country's total linkage strength. If there were a tight relationship, we would expect to see the rankings of the local linkage scores closely align with the ranking of the country's total linage strength. Figure 2, which presents a box plot of the point estimates of the ranks of the margins-adjusted local linkage scores for countries sorted by their adjusted total linkage (including general education), shows that this is not true.16 Of course, there must be a relationship between the rankings of local linkage scores and the ranking of total linkage strength because the latter is a weighted average of the former, and it is apparent in Figure 2 that countries with higher total M generally have pathways with higher ranks of their local linkage scores. At the same time, we see substantial heterogeneity that goes well beyond the uncertainty produced by standard errors. One also sees country differences in the internal coherence of their pathway structure. For example, Germany has a tighter box than does Hungary, Austria, or Spain (which have larger sample sizes than Germany - see Table A.1) even though those countries all have higher total linkage strength than Germany. Figure 2 is an important reminder of the limitations

\footnotetext{
${ }^{15}$ About $20 \%$ of the variation by country in lower-tertiary linkage is attributable to country differences in occupational marginals. This rises to $30 \%$ for non-tertiary linkage and to $40 \%$ for upper-tertiary marginals.

${ }^{16}$ The box plot shows the minimum, maximum, median, and the scores at the 25 th and 75 th percentile for each country. Point estimates of the local linkage scores themselves, along with standard errors, are available upon request.
} 
of only paying attention to national-level institutions when investigating the nature and consequences of skill formation systems.

Figure 2: Box Plot of the Rank of Pathway Strength, sorted by Adjusted Total Linkage Strength of Countries

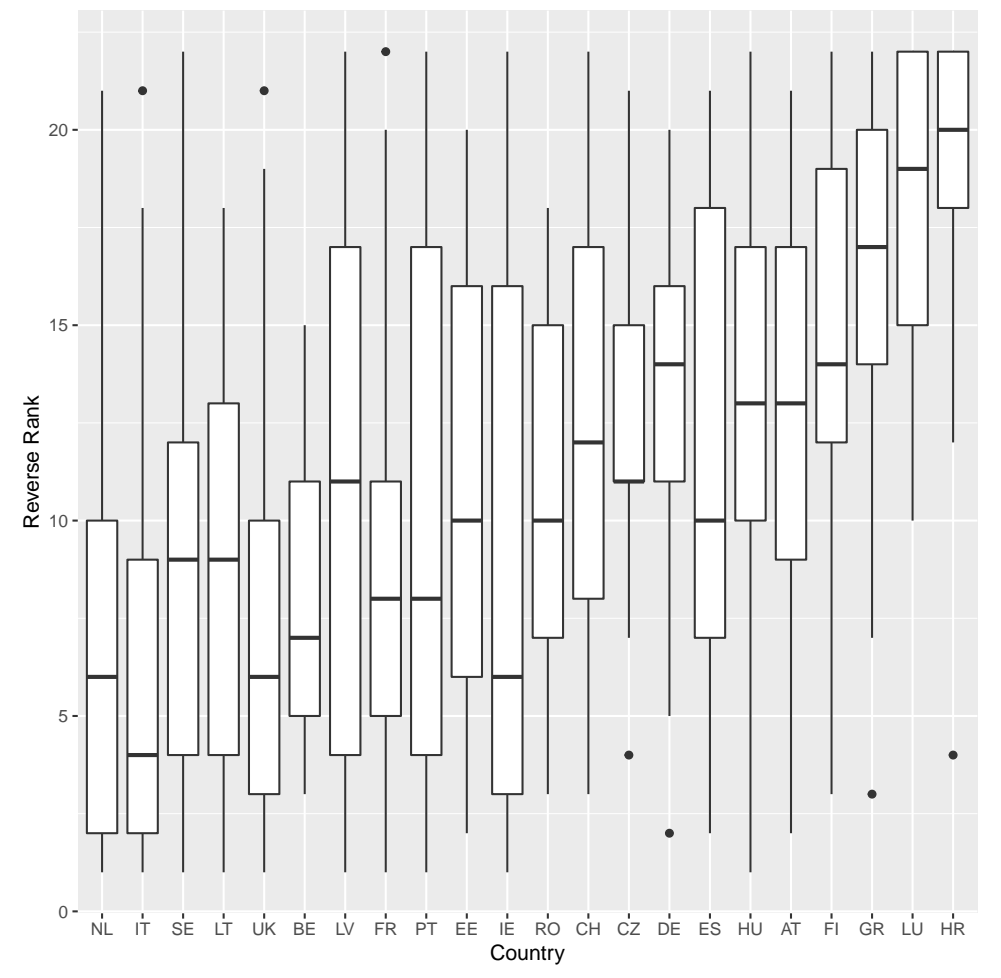

Next, we briefly consider in the text (and then at greater length in the appendices) the issues of heterogeneity in local linkage strength by educational level, by age, and by employment relationship. As we discussed earlier in this paper, the literature on skill formation systems has found it difficult to produce a theoretically unified perspective across the different levels of the educational system. This would be more surprising if countries with tight linkage at lower educational levels also had tight linkage at the upper-tertiary level. It would be less surprising if total linkage strength at one level is a poor predictor of total linkage strength at a different level. We address this question in Appendix $\mathrm{C}$ and conclude that the correlation between linkage strength at upper-tertiary and at lower educational levels is relatively weak, which is consistent with the idea that there is relatively weak institutional coupling between these two levels of education in many countries.

How similar are local linkage scores computed for the whole sample and for subsamples of younger or older workers? The Pearson correlation between the 550 (including general-education non-tertiary workers) local linkage scores computed on the marginadjusted full sample and those computed only on workers who are 45 years old or younger 
is 0.97. The corresponding correlation between scores from the full sample and those obtained from a subsample of workers older than 45 is 0.95 . We discuss the few noteworthy differences between the rankings of countries in the total $M$ of the subsamples in Appendix D. When considering the entire set of countries, we see the very high correlations in adjusted local linkage strength between the scores from the total sample and the scores from the age subsamples as supporting the use of a single set of local linkage scores in the analyses that follow.

Lastly, we note that other scholars (Kalleberg 2018) have found that the proportion of all workers who are permanent, full time workers varies considerably from one country to another. This raises the question of whether country variation in the distribution of employment relationships might be a major source of country differences in linkage strength for specific educational credentials. We explore this question in some detail in Appendix E. We find that linkage strength varies as one might expect, namely that workers in fulltime, permanent jobs have stronger linkage between educational credentials and occupations. At the same time, these variables explain only a small proportion of the variation in local linkage strength across level-fields either within countries or across countries.

\subsection{The Empirical Grouping and Scoring of Countries}

Because linkage strength is a multidimensional concept that can be calculated both before and after adjusting for country differences in marginal distributions, there are multiple ways to form a grouping or scoring of countries. Countries can be ranked on total linkage strength $(M)$ computed from the unadjusted data for each country. They can be ranked instead on the total linkage strength computed from data that have been adjusted to have the same educational and occupational distribution for each country (adjusted $M$ ) by using IPF to adjust all countries to the same educational and occupational marginal distributions.

Countries can also be grouped or ranked in terms of their "distance" from other countries in their set of local linkage scores. Because country differences among local linkage scores could have different signs, a similar value of total linkage strength does not mean that two countries necessarily have a similar pattern of local linkage scores. In order to assess the similarity of local linkage scores across countries, we compute the distance of each country from the other across the dimensional space defined by the local linkage scores for educational outcomes. The concept of distance that we find most appealing and empirically useful is that of Manhattan distance, which involves the sum of absolute distances 
between each of the local linkage scores (Black 2006). 17 We further apply a weighted Manhattan metric where we weight each of the pair of local linkage strength measures by the proportion of the workforce that is in that educational categories (to keep the weights uniform, we use the distribution obtained from the "super-country" defined by the set of countries in our analysis).

Manhattan distances necessarily exist in a high dimensional space. In Figure 3, we provide a representation of these distances in two dimensions using a dendrogram computed from margin-adjusted tables that exclude general education non-tertiary workers. As can be seen in Figure 3, a set of nine countries (Germany, Austria, Switzerland, Finland, Hungary, the Czech Republic, Spain, Romania, and Ireland) are close to each other either in terms of Manhattan distance. Another group of countries (Greece, Croatia, and Luxembourg) have high values of adjusted $M$ but are more distant in their array of local linkage scores from this group of eight. A third group of countries (Latvia, Lithuania, and Estonia), have a similar pattern of local linkage scores but have values of adjusted $M$ that put them in the bottom half of countries. Finally, the United Kingdom, France, Belgium, the Netherlands, Sweden, Italy, and Portugal group together as having relatively low total linkage strength and are relatively close to each other in terms of their Manhattan distance.

Table 1 shows country groupings based on the adjusted $M$ (see Figure 1), the proportion in licensed occupations from Koumenta and Pagliero (2017) (their proportions are reproduced in Table A.4), a ranking based on the dendrogram in Figure 3, and, for reference, the unadjusted $M$ (see Figure 1). We use these dimensions to create three alternative grouping schemes, which produce what we will refer to in each case as a group of high linkage countries and a group of low linkage countries.

\footnotetext{
${ }^{17}$ While Euclidean distance could in principle be used as the distance metric (as could a number of other metrics), there are indications from the literature that Euclidean distance does not perform well when the dimensionality of the space is high (Aggarwal, Hinneburg, and Keim 2001). Manhattan distance is sometimes referred to as "taxi distance" because in two dimensions it is the distance a taxi would travel in a rectangular grid to get from point $\mathrm{A}$ to point $\mathrm{B}$.
} 
Figure 3: Dendrogram of Manhattan distances on Margin-Adjusted Local Linkage Scores

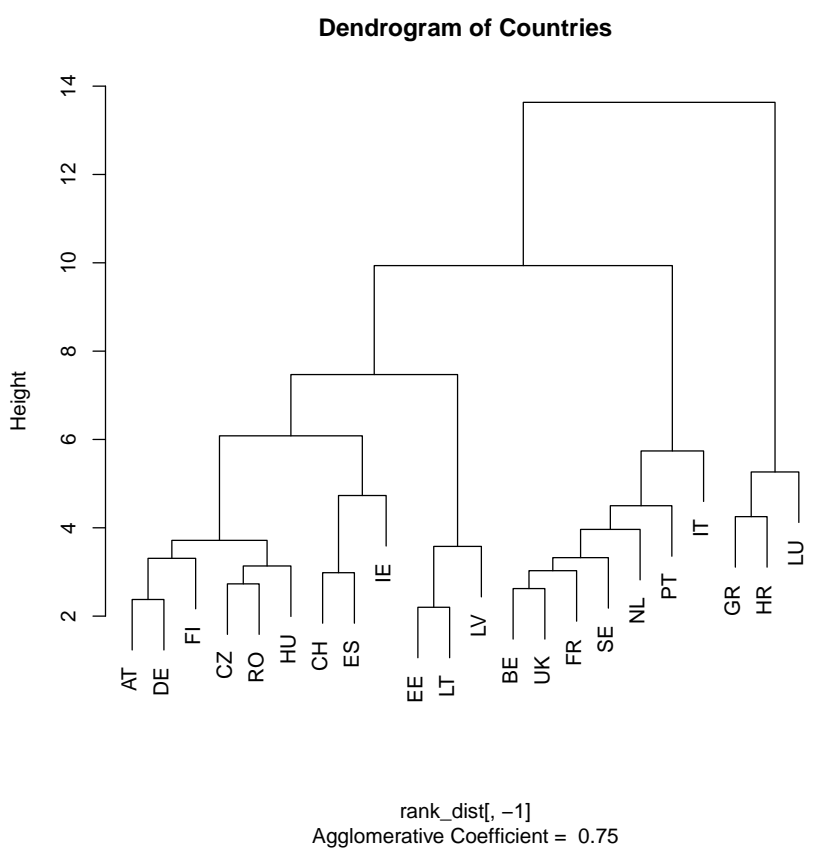

The first grouping (grouping A) puts the set of countries with the highest scores on adjusted $\mathrm{M}$ for the total sample in the "high linkage" group and the other countries in the "low linkage" group.The second grouping (grouping B) modifies grouping A by also paying attention to the rankings of countries based on the proportion working in licensed occupations (Koumenta and Pagliero 2017; see Table A.4); specifically it adds Ireland and the Netherlands and removes Finland and Spain from the high linkage group. Ireland and the Netherlands are added because they have a high proportion of workers in licensed occupations (Ireland ranks \#3 respectively on this criteria, while the Netherlands ranks \#6). Spain (\#15) and Finland (\#18) are removed because they rank relatively low in licensing coverage. 18 We note that by introducing a grouping criterion based on something other than linkage strength (i.e., proportion licensed), we create a grouping scheme that is potentially noisier than the groupings obtained purely from information about local linkage and total adjusted linkage strength. We include this additional scheme because licensing has been recognized as an important mechanism for occupational closure and it typically involves educational requirements. It becomes a robustness check on the extent to which an alternative reasonable grouping criterion produces the same pattern of outcomes as we obtain using linkage strength as the basis for defining similarity across countries in skill formation systems.

\footnotetext{
${ }^{18}$ Sweden is excluded because there is no earnings information for Swedish respondents in the EU LFS for the years we analyze.
} 
The third grouping (grouping C) uses Manhattan distances, which pay greater attention to the pairwise differences in local linkage scores; it groups only the subset of countries within one of the two largest clusters seen in the dendrogram; this is an attempt to remove "mixed cases" from the comparison in order to get a clearer assessment of group differences. We note that the grouping of countries into high linkage and low linkage countries from Figure 3 yields identical groups regardless of whether or not the general-education non-tertiary workers are included.

How do these groups compare with the groups proposed in the CASMIN or the VoC literature? Our results agree with groups formulated on institutional criteria in many but not all instances. Germany has a relatively high total linkage score regardless of whether one measures it from the joint distribution of educational and occupational categories or from this distribution after adjusting the marginals. However, while Switzerland and Austria also rank relatively highly, the Netherlands actually has low total linkage strength despite having a well developed vocational educational system, perhaps because its vocational system is more school based and less apprentice based. Recall that Hall and Gingerich (2009) placed Germany, Switzerland, the Netherlands, Belgium, Sweden, Finland, and Austria in the coordinated market economy group. Four of these countries have relatively strong total linkage strength, but three of them (the Netherlands, Belgium, and Sweden) have weaker total linkage strength, which puts them with the market-liberal UK and the - for the VoC literature - "mixed case" countries of France and Italy. These disagreements point to the fact that countries differ from each other in multiple ways even as individual countries are internally heterogeneous. Both of these realities resist unambiguous classification of countries into groups. The advantage of ranking and grouping based on linkage strength is that this approach uses criteria that are rigorously justified in the literature on multi-group segregation. We consider the importance of these macrogroupings in explaining outcomes later in the paper. 
Table 1: Empirical Group Ranks and Alternative Country Groupings

\begin{tabular}{|c|c|c|c|c|c|c|c|}
\hline \multirow[t]{2}{*}{ Country } & \multicolumn{4}{|c|}{ Criterion } & \multicolumn{3}{|c|}{ Groupings } \\
\hline & M & Adjusted M & \%licensed & Manhattan & A & B & $\mathrm{C}$ \\
\hline Greece & 1 & 1 & 1 & 4 & $\mathrm{H}$ & $\mathrm{H}$ & - \\
\hline Luxembourg & 1 & 1 & 1 & 4 & $\mathrm{H}$ & $\mathrm{H}$ & - \\
\hline Finland & 1 & 1 & 2 & 1 & $\mathrm{H}$ & $\mathrm{L}$ & $\mathrm{H}$ \\
\hline Germany & 1 & 1 & 1 & 1 & $\mathrm{H}$ & $\mathrm{H}$ & $\mathrm{H}$ \\
\hline Croatia & 1 & 1 & 1 & 3 & $\mathrm{H}$ & $\mathrm{H}$ & - \\
\hline Switzerland & 1 & 1 & - & 1 & $\mathrm{H}$ & $\mathrm{H}$ & $\mathrm{H}$ \\
\hline Czech Rep & 2 & 1 & 1 & 1 & $\mathrm{H}$ & $\mathrm{H}$ & $\mathrm{H}$ \\
\hline Hungary & 1 & 1 & 1 & 1 & $\mathrm{H}$ & $\mathrm{H}$ & $\mathrm{H}$ \\
\hline Austria & 2 & 1 & 1 & 1 & $\mathrm{H}$ & $\mathrm{H}$ & $\mathrm{H}$ \\
\hline Romania & 2 & 1 & 1 & 1 & $\mathrm{H}$ & $\mathrm{H}$ & $\mathrm{H}$ \\
\hline Spain & 1 & 1 & 2 & 1 & $\mathrm{H}$ & $\mathrm{L}$ & $\mathrm{H}$ \\
\hline Lithuania & 2 & 2 & 2 & 4 & $\mathrm{~L}$ & $\mathrm{~L}$ & - \\
\hline Estonia & 2 & 2 & 2 & 3 & $\mathrm{~L}$ & $\mathrm{~L}$ & - \\
\hline Latvia & 2 & 2 & 2 & 3 & $\mathrm{~L}$ & $\mathrm{~L}$ & - \\
\hline Sweden & 1 & 2 & 2 & 2 & - & - & - \\
\hline Belgium & 1 & 2 & 2 & 2 & $\mathrm{~L}$ & $\mathrm{~L}$ & $\mathrm{~L}$ \\
\hline Portugal & 2 & 2 & 2 & 2 & $\mathrm{~L}$ & $\mathrm{~L}$ & $\mathrm{~L}$ \\
\hline Ireland & 1 & 2 & 1 & 1 & $\mathrm{~L}$ & $\mathrm{H}$ & $\mathrm{H}$ \\
\hline France & 2 & 2 & 2 & 2 & $\mathrm{~L}$ & $\mathrm{~L}$ & $\mathrm{~L}$ \\
\hline UK & 2 & 2 & 1.5 & 2 & $\mathrm{~L}$ & $\mathrm{~L}$ & $\mathrm{~L}$ \\
\hline Netherlands & 2 & 2 & 1 & 2 & $\mathrm{~L}$ & $\mathrm{H}$ & $\mathrm{L}$ \\
\hline Italy & 2 & 2 & 2 & 2 & $\mathrm{~L}$ & $\mathrm{~L}$ & $\mathrm{~L}$ \\
\hline
\end{tabular}

Note: "H" refers to the high-linkage group and "L" refers to the low-linkage group. The UK is assigned a score of 1.5 on the percent licensed measure because it ranked exactly in the middle (11th of 21) based either on the proportion of the workforce that is licensed (Koumenta and Pagliero 2017; these proportions are reproduced in Table A.4p). The numbers in the Manhattan column refer to the four clusters visible in the dendrogram in Figure 3. Sweden is excluded from the final country groupings because of the lack of earnings information for Sweden. See text for further details.

\subsection{Linkage and Occupational Matching}

It stands to reason that if strong local linkage creates more orderly pathways between educational outcomes and the occupational structure, then we would expect pathways with stronger local linkage to also be pathways where a higher percentage of workers obtain good occupational matches. We would further expect countries with stronger total linkage to have a higher proportion of workers who are well matched. To assess the connection between local linkage and matching, we estimated linear probability models with fixed effects for educational pathways and countries to assess the strength of the connection be- 
tween local linkage strength and the probability of working in one of the two most strongly matching occupations. Table 2 shows the relationship between local linkage strength and matching. The results show that the proportion who match well generally rises with local linkage strength. 19 An increase of about 0.5 in local linkage strength 20 corresponds to an increase of 7.5 percentage points in the percentage of workers who are in one of the two best matching occupations (7.7 percentage for the three best matching occupations). and an increase of 0.8 in the rank of the occupation one works in.21

Table 2: Effect of Local Linkage Strength on Occupational Match Quality

\begin{tabular}{|c|c|c|c|}
\hline & top 2 & top 3 & rRank \\
\hline \hline local linkage & $.150(.002)$ & $.154(.002)$ & $1.581(.020)$ \\
\hline gender & $-.023(.0007)$ & $-.014(.0008)$ & $-.022(.007)$ \\
\hline age & $-.003(.0002)$ & $-.003(.0002)$ & $-.043(.002)$ \\
\hline age2 & $.000023(.000002)$ & $.000016(.000003)$ & $.00039(.00002)$ \\
\hline level-field FE & yes & yes & yes \\
\hline detailed levels & yes & yes & yes \\
\hline country FE & yes & yes & yes \\
\hline $\mathrm{N}$ & $1,273,653$ & $1,273,653$ & $1,273,653$ \\
\hline
\end{tabular}

What is the picture at the national level? Table A.4 shows the proportion of all workers who are well matched in terms of being in the top 2 or 3 occupations. It also shows the mean rank when everyone is scored in terms of which occupation they work in, using 10 for the top occupation down to 1 for the 10th occupation and zero for working in an occupation outside of the top 10 . The highest country approaches having $1 / 3$ of its workers in one of the top two occupations and approaches $40 \%$ being in one of the top three occupations. These percentages, of course, mask considerable variation from one educational outcome to another. The ranking is generally in agreement with the rankings of countries in terms of their unadjusted total linkage strength. Some countries may seem to be out of line, but it is important to note first that the statistics in Table A.4 are affected by their (differing) marginal distributions and second that the $M$ is affected by the location of workers in the occupational distribution outside the top occupations as well as by the proportion that are located in one of these top occupations. To take only one example,

\footnotetext{
${ }^{19}$ Table 2 also shows that women typically do not match as well as men, and that the proportion who match well gradually declines with age.

${ }^{20} \mathrm{An}$ increase of 0.5 is roughly the mean difference in $M$ between the high linkage and the low linkage countries - see Figure 1 - and is only slightly larger than the average standard deviation in local linkage strength across countries for specific level-fields - see Table B.1.

${ }^{21}$ With this measure, occupations are assigned scores based on their ranking on the measure of matching, with zero being the score for an occupation that is not one of the 10 most common destinations, and the ten most common occupations given scores from 1 (weakest match) to 10 (strongest match).
} 
the proportion of workers matching in the Czech Republic seems low relative to how this country is classified in Table 3, but one can see in Figure 1 that the unadjusted $M$ of the Czech Republic is relatively low because of that country's particular distribution of workers across educational credentials. When the educational marginals of the Czech Republic are adjusted to the common standard, its $M$ increases. Later in the paper, we address the implications of using gender-common or gender-specific scores for measuring the quality of occupational matching.

\subsection{Linkage, Matching, and Earnings}

We examine the impact of local linkage strength on relative net earnings using the fixed effects regression strategy described above with margins-adjusted local linkage scores. Table 3 shows in the left column the estimated total effect of local linkage strength on income decile, controlling for for gender, linear and quadratic effects of age, country fixed effects, level-field fixed effects, and detailed controls for educational level differences beyond what is captured in the level-field fixed effects. The next column adds employment relationship as a control, and the subsequent columns show how match quality affects income for three different ways to operationalize match quality. Because local linkage strength affects match quality as well as earnings, the first two columns show the total effect of local linkage strength on the outcome and thus are labeled as the "total effects" of local linkage strength in the column headings. The total effects model shows that, across the set of 21 countries, a country with relatively strong linkage for any particular educational credential tends to have relatively high earnings by workers with that credential. An increase of about 0.5 in local linkage strength corresponds to an increase of about 2 percentage points in earnings rank.22

\footnotetext{
${ }^{22} \mathrm{~A}$ difference of 0.5 is roughly the mean difference in $M$ between the high linkage and the low linkage countries - see Figure 1 -, and is only slightly larger than the average standard deviation in local linkage strength across countries for specific level-fields - see Table B.1.
} 
Table 3: Effects of Linkage and Match Quality on Net Earnings.

\begin{tabular}{|c|c|c|c|c|c|c|}
\hline & \multicolumn{3}{|l|}{ Total Effects Model } & \multicolumn{3}{c|}{ Full Model (Different Measures of Match } \\
& & & \multicolumn{3}{c|}{ Quality) } \\
\hline \multirow{2}{*}{ linkage strength } & .416 & .389 & .166 & .158 & .148 & -.127 \\
& $(.013)$ & $(.012)$ & $(.014)$ & $(.012)$ & $(.013)$ & $(.014)$ \\
\hline good match & & & -.001 & -.133 & -.072 & -.019 \\
& & & $(.013)$ & $(.011)$ & $(.010)$ & $(.001)$ \\
\hline match*linkage strength & & & .536 & .538 & .440 & .079 \\
& & & $(.011)$ & $(.010)$ & $(.009)$ & $(.001)$ \\
\hline Part-time permanent & & -2.44 & & -2.42 & -2.42 & -2.42 \\
& & $(.006)$ & & $(0.006)$ & $(.006)$ & $(.006)$ \\
\hline Full-time temporary & & -1.18 & & -1.17 & -1.17 & -1.15 \\
& & $(.008)$ & & $(.008)$ & $(.008)$ & $(.008)$ \\
\hline Part-time temporary & & -3.42 & & -3.39 & -3.39 & -3.37 \\
& & $(.011)$ & & $(.011)$ & $(.011)$ & $(.011)$ \\
\hline $\mathrm{N}$ & & $1,273,653$ & $1,273,653$ & $1,273,653$ & $1,273,653$ & $1,273,653$ \\
\hline
\end{tabular}

Note: Models control for gender, linear and quadratic effects of age, country fixed effects, level-field fixed effects, and detailed controls for educational level differences beyond what is captured in the level-field fixed effects. As indicated, models also control for type of employment relationship. Results using "top 2," "top 3," and "Rank" are indicated in the column headings. The rank measure is reverse rank, i.e., the top rank is 10 , next is 9 , etc, as described in the text.

The last four columns of Table 3 show that the earnings gap between well-matched and less-well-matched workers in any particular level-field is generally larger in countries where the local linkage strength for that credential is greater. To put it another way, for workers in a good match, there is a benefit to being in a country where the local linkage strength for that credential is high. An additional 0.5 of local linkage strength corresponds to a relative gain of 2.7 percentage points in the country's earnings distribution relative to workers with that same educational credential who are not well matched using the top 2 measure, and 2.2 percentage points using the top 3 measure. The reverse rank measure does not produce a binary contrast, but local linkage strength clearly enhances the value of being in a higher ranking occupation. A 0.5 additional local linkage strength increases relative earnings by two percentage points for being in an occupation that is 5 ranks higher in the matching criterion. Part-time workers obviously have lower earnings than do full-time workers with the same credential. Similarly, temporary workers have lower relative earnings than do permanent workers with the same educational credential. But, compared to these effects, the impact of local linkage strength is far from negligible. An increase of 0.5 in local linkage strength increases the earnings gap between well matched and less-well matched workers by between $20 \%$ and $25 \%$ of the estimated earn- 
ings gap between permanent and temporary full-time workers.23

The employment relationship variables could be considered outcome variables and hence endogenous to education, while at the same time monthly take home earnings will certainly depend on whether a job is part-time or full time as well as whether it is permanent or temporary. For our immediate purposes, the clear result from Table 3 is that whether or not we include the employment relationship categories in the model does not have a big impact on the relationship between local linkage strength or match quality and net earnings.24 The tables below include controls for the type of employment relationship.

Table 4 shows the total effects of linkage strength on relative earnings for the full sample and then broken down by age and gender groups. The table also shows the total effects of local linkage separately by educational level. The results reaffirm that local linkage strength has an important total effect on earnings across the entire sample, but also reveal noteworthy heterogeneity in the effects of local linkage strength.

In general, the effects are stronger for women than for men, though the effects for young men are quite strong as well. Effects of pathway strength on earnings are weakest for older male workers, particularly when general education non-tertiary workers are included in the analysis.

When the analysis is broken down by educational level, we see that the total effect of local linkage is most strongly positive for non-tertiary and lower tertiary workers. For upper-tertiary workers, the total effect varies between positive and negative depending on the age-gender group, though (as we will see below), this does not mean that local linkage is unimportant.

The results in Table 4 also show that models estimated on the entire sample underestimate the importance of local linkage strength for non-tertiary workers relative to the effects estimated for each of the age-gender groups. The reason for this is the importance of interaction effects involving gender and field of study, which are absent from the fullsample models but are of course present in the models estimated separately by age and gender.

The results also qualify the apparent unimportance of local linkage strength for older male workers. In fact, the total effect of local linkage strength for older male workers is very important for non-tertiary workers, particularly those who were educated in a particular field of study at the non-tertiary level. It is only at the tertiary level where total effects of local linkage are zero or slightly negative. We note, however, that $2 / 3$ of the older

\footnotetext{
${ }^{23}$ The calculation uses the "top two" measure for match quality.

${ }^{24}$ The coefficient pattern is similar when we control for usual hours of work instead of the fulltime/part-time distinction.
} 
men in these samples were educated at the non-tertiary level and also, as we will see below, a low total effect of local linkage does not mean that local linkage is inconsequential for labor market outcomes.

Table 4: Total Effects of Local Linkage Strength, by Educational Level

\begin{tabular}{|c|c|c|c|c|c|c|}
\hline & $\begin{array}{c}\text { Employed, All } \\
\text { Categories }\end{array}$ & $\begin{array}{c}\text { Employed, } 24 \\
\text { Categories }\end{array}$ & $\begin{array}{c}\text { Employed, } \\
\text { Non-Tertiary, } 9 \\
\text { Categories }\end{array}$ & $\begin{array}{c}\text { Employed, } \\
\text { Non-Tertiary, } 8 \\
\text { Categories }\end{array}$ & $\begin{array}{c}\text { Employed, } \\
\text { Lower-Tertiary }\end{array}$ & $\begin{array}{c}\text { Employed, } \\
\text { Upper-Tertiary }\end{array}$ \\
\hline Full sample & $.389(.012)$ & $.393(.013)$ & $.142(.022)$ & $.131(.025)$ & $.629(.026)$ & $-.043(.023)$ \\
\hline $\mathrm{N}$ & $1,273,653$ & $1,118,073$ & 854,863 & 699,283 & 110,289 & 308,501 \\
\hline $\begin{array}{c}\text { Men, } \\
<45 \text { years }\end{array}$ & $.381(.023)$ & $.364(.024)$ & $.243(.046)$ & $.198(.050)$ & $.391(.054)$ & $.256(.044)$ \\
\hline $\mathrm{N}$ & 388,325 & 347,692 & 276,927 & 236,294 & 30,294 & 81,104 \\
\hline $\begin{array}{c}\text { Men, } \\
45+\text { years }\end{array}$ & $.054(.030)$ & $.107(.032)$ & $.321(.064)$ & $.715(.070)$ & $.002(.079)$ & $-.115(.049)$ \\
\hline $\mathrm{N}$ & 255,413 & 230,867 & 177,217 & 152,671 & 18,659 & 59,537 \\
\hline $\begin{array}{l}\text { Women, } \\
<45 \text { years }\end{array}$ & $.567(.021)$ & $.571(.022)$ & $.468(.037)$ & $.502(.043)$ & $.781(.039)$ & $-.088(.045)$ \\
\hline $\mathrm{N}$ & 385,266 & 333,417 & 238,362 & 186,513 & 39,595 & 107,309 \\
\hline $\begin{array}{l}\text { Women, } \\
45+\text { years }\end{array}$ & $.442(.027)$ & $.488(.029)$ & $.334(.047)$ & $.238(.056)$ & $.691(.058)$ & $.106(.057)$ \\
\hline $\mathrm{N}$ & 244,649 & 206,097 & 162,357 & 123,805 & 21,741 & 60,551 \\
\hline
\end{tabular}

Figure 4 shows the estimated relationship between relative earnings and local linkage strength for well-matched (in blue) and less-well-matched (in red) workers, where the black vertical lines show the mean (solid line) and one and two standard deviations (dashed lines) of the local linkage strength distribution for each subgroup. The first two columns of Figure 4 provide estimates broken down by age and gender group for all educational levels combined, where the first column uses all 25 educational categories, and the second column excludes the non-tertiary general education category. There are two points to highlight in the results in the first two columns. The first is that the overall pattern discussed above - namely that earnings are generally higher when one's educational credentials have stronger local linkage - is somewhat more pronounced for female workers than for male workers. The second point is that the earnings gap between well-matched and less-well-matched workers rises with the strength of local linkage for all four age-gender groups. 


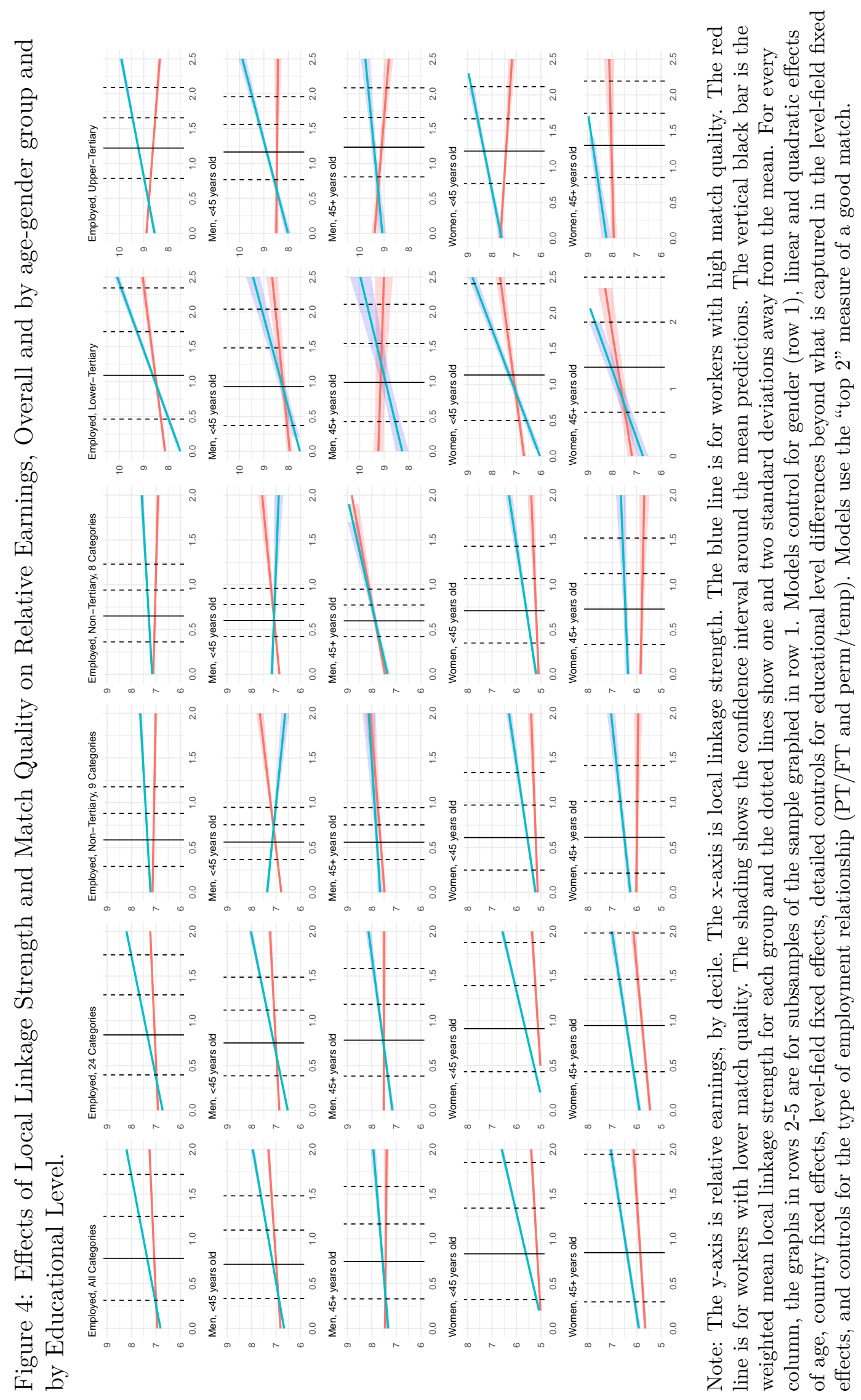


The last four columns of Figure 4 show the effects of local linkage strength and the quality of the match on earnings outcomes separately for the three educational levels. The top row shows the estimates for all workers taken together, and the next four rows show the results broken down by age and gender group. Reading across the columns in the top row, we see that lower-tertiary workers generally benefit from greater local linkage strength even if they are not well-matched, but clearly the returns to local linkage strength are stronger for the well-matched workers. For upper-tertiary workers, stronger local linkage produces higher relative earnings only for the workers who are themselves well matched. In other words, greater local linkage strength increases the pay gap between well matched and less well matched workers at both tertiary education levels. The pattern for non-tertiary workers in the top row of Figure 4 is similar to that for tertiaryeducated workers; however, the benefit of local linkage strength for matched workers is weaker and the earnings gap between well-matched and less-well-matched non-tertiary workers is smaller than is the case for lower or upper tertiary-educated workers.

The pattern for the four age-gender groups is generally similar to the overall pattern. However, this overall pattern is not maintained for all combinations when we simultaneously break down the data by age-gender groups and by educational levels. In particular, younger men with non-tertiary education do not benefit from stronger local linkage when they are occupationally well matched to their field of study.25 This pattern is perhaps ironic in that it is arguable that young men with non-tertiary education have been the central focus of the institutional literature discussed earlier in this paper, and highlinkage countries are expected to have high local linkage and a correspondingly high return for being well matched.

To understand why this one age-gender group in this one educational level has a negative relationship between relative earnings and local linkage strength, we investigated the patterns for individual groups and fields within the non-tertiary group. First, we note that the negative slope for younger men is not present for the other three age-gender groups including in particular younger women, who show a strong positive effect of local linkage strength on earnings. Second, we note that the negative slope for younger men is more pronounced when the general education category is included (column 3, "9 categories"). In general, local linkage of non-tertiary general education is very weak (see Table B.1), and it is not surprising that stronger local linkage for someone with non-tertiary general education does not produce economic benefits. Third, we found that the slope of the earningslocal linkage strength relationship shifts from significantly negative to significantly positive

\footnotetext{
${ }^{25}$ We also obtain a negative slope when we operationalize matching using the top three matching occupations or using the matching rank of the ten most common occupations.
} 
if we remove the agriculture/forestry/fishing/veterinary field and also the services field. Agricultural occupations generally do not pay well, and so it is perhaps not surprising that stronger local linkage would not contribute to higher earnings. Concerning services, we note that the top two matching occupations are "housekeeping and restaurant services workers" and "other personal services workers." Personal services workers - at least - are female-dominated as are many other occupations in the services category, and men would not generally expect to be relatively well paid when working in female-dominated occupations. In Tables A.5 and A.6, we display occupational matches when we separate the sample into male and female workers and apply the same logic to compute high quality matches as described above. The top two male matches for the non-tertiary services credential substitutes locomotive engine drivers and related workers for other personal services workers. However, it does not qualitatively change the pattern for non-tertiary educated workers or, indeed, for any of the other models displayed in Figure 4 . This can be seen by comparing the results from Figure 4 with the results using match quality computed from data restricted to either men or to women, which are displayed in Figure A.1.

\subsection{Country-Level Effects}

A country's total linkage strength is, of necessity, associated in a multi-country analysis with the strength of local linkages of the educational pathways in that country. But does the total linkage strength of a country matter for labor market outcomes after taking account of the local linkage strength of a worker's educational credential? We examine the effect of system-level linkage strength using two strategies: a between-country-group strategy and a within-country-group/between-country strategy. In the first, between-countrygroup strategy, we estimate a regression with level-field fixed effects, detailed countryspecific effects of educational level, and also controls for gender, age, and employment relationship. We also include terms for (1) the strength of local linkage for the educational credential, (2) the quality of the occupational match, (3) whether the country is a highlinkage or a low-linkage country using the three different country grouping schemes in Table 1, and (4) an interaction between local linkage strength and country type. In the second, within-country-group/between-country strategy, we estimate separate regressions using the same specification that was used in section 4.5 for the set of high-linkage countries and then again for the set of low-linkage countries, where these groups are defined using the three country grouping schemes shown in Table 1. This second strategy examines whether country differences in local linkage strength matter differently among the high-linkage countries than among the low-linkage countries. 
Table 5, which shows the results from the first strategy, agrees with the results of Table 3 that the strength of local linkage is associated with higher relative earnings. It further reports that the association between local linkage strength and relative earnings is stronger in high linkage countries than in low linkage countries for all three grouping criteria, and for both men and women. However, we do not see these results as definitive because the coefficients of the between-country-group model (high-linkage countries vs lowlinkage countries) are identified by the strong assumption that country fixed effects are not relevant except insofar as they indicate whether a country is a high linkage or a low linkage country. This assumption is likely to be violated in practice.

Table 5: Effects of Local Linkage and Match Quality on Relative Pay in High and Low Linkage Countries

\begin{tabular}{|c|c|c|c|c|c|c|}
\hline & \multicolumn{7}{|c|}{ Grouping A } & \multicolumn{2}{c|}{ Grouping B } & \multicolumn{2}{c|}{ Grouping C } \\
\hline & \multicolumn{7}{|c|}{ Men } \\
\hline local linkage & $.738(.020)$ & $.718(.020)$ & $.954(.018)$ & $.925(.018)$ & $1.000(.022)$ & $.976(.022)$ \\
\hline high group & $-.216(.013)$ & $-.224(.013)$ & $-.017(.013)$ & $-.022(.013)$ & $-.327(.015)$ & $-.335(.015)$ \\
\hline linkage*high & $.568(.015)$ & $.563(.015)$ & $.401(.015)$ & $.395(.015)$ & $.700(.017)$ & $.694(.017)$ \\
\hline good match & & $.222(.008)$ & & $.219(.008)$ & & $.218(.009)$ \\
\hline $\mathrm{N}$ & 643,738 & 643,738 & 643,738 & 643,738 & 558,298 & 558,298 \\
\hline & & & & & \\
\hline local linkage & $.753(.017)$ & $.644(.017)$ & $.817(.016)$ & $.696(.016)$ & $.830(.019)$ & $.718(.019)$ \\
\hline high group & $-.535(.012)$ & $-.517(.012)$ & $-.150(.012)$ & $-.153(.012)$ & $-.611(.013)$ & $-.588(.013)$ \\
\hline linkage*high & $.668(.011)$ & $.631(.011)$ & $.385(.012)$ & $.368(.012)$ & $.724(.012)$ & $.685(.012)$ \\
\hline good match & & $.704(.008)$ & & $.711(.008)$ & & $.694(.009)$ \\
\hline $\mathrm{N}$ & 629,915 & 629,915 & 629,915 & 629,915 & 540,256 & $.753(.017)$ \\
\hline
\end{tabular}

Note: The models controls for employment relationship, fixed effects for level-field, detailed educational level, gender, and linear and quadratic effects of age. Match quality is measured using the "top two" criterion.

For more compelling evidence, therefore, we turn to our second strategy and estimate models that include fixed effects for countries as well as fixed effects for level-fields. These results basically replicate the estimates that were shown above in Table 4 and in Figure 4 except that we report results separately for high- and low-linkage countries by our three grouping criteria. In the interests of parsimony, we also reduce the number of subgroup analyses from these tables when this does not obscure the overall picture. In the first step, we focus on whether the total effect of local linkage strength differs according to whether the country is in the high-linkage or low-linkage group and by age and gender. The result from the first row of Table 6, which is estimated with a sample consisting of all four age-gender groups, is that strong local linkage provides an earnings advantage in both 
high-linkage and low-linkage countries; this is true for all three country grouping schemes shown in Table 1. The effect is bigger in high linkage countries than in low linkage countries for the "A" and the "B" grouping schemes, but high- and low-linkage countries have similar effects in the "C" grouping scheme. When we look at age-gender subgroups, we see bigger local linkage effects in high linkage countries than in low-linkage countries for male workers in both age groups and for older female workers. The expected pattern, however, is not present in the sample of younger women workers.

Table 6: Total Effects of Local Linkage and Match Quality on Net Earnings for Country Group by Age-Gender group

\begin{tabular}{|c|c|c|c|c|c|c|}
\hline \multirow[b]{3}{*}{ Coefficient } & \multicolumn{6}{|c|}{ Country Grouping Scheme } \\
\hline & \multicolumn{2}{|c|}{ A } & \multicolumn{2}{|c|}{ B } & \multicolumn{2}{|c|}{$\mathrm{C}$} \\
\hline & High & Low & High & Low & High & Low \\
\hline \multicolumn{7}{|c|}{ All age-gender groups } \\
\hline local linkage & $.427(.019)$ & $.376(.019)$ & $.492(.021)$ & $.268(.019)$ & $.380(.021)$ & $.393(.022)$ \\
\hline $\mathrm{N}$ & 763,911 & 509,742 & 782,165 & 491,488 & 701,282 & 397,272 \\
\hline \multicolumn{7}{|c|}{ Women $<45$} \\
\hline local linkage & $.585(.034)$ & $.616(.031)$ & $.559(.036)$ & $.539(.031)$ & $.497(.037)$ & $.640(.037)$ \\
\hline $\mathrm{N}$ & 220,621 & 164,645 & 231,606 & 153,660 & 205,228 & 126,422 \\
\hline \multicolumn{7}{|c|}{ Men $<45$} \\
\hline local linkage & $.316(.034)$ & $.230(.037)$ & $.278(.038)$ & $.218(.037)$ & $.311(.040)$ & $.211(.041)$ \\
\hline $\mathrm{N}$ & 243,655 & 144,670 & 246,693 & 141,632 & 219,415 & 117,982 \\
\hline \multicolumn{7}{|c|}{ Women $>=45$} \\
\hline local linkage & $.727(.046)$ & $.500(.040)$ & $.846(.047)$ & $.321(.040)$ & $.646(.048)$ & $.619(.049)$ \\
\hline $\mathrm{N}$ & 138,782 & 105,867 & 142,703 & 101,946 & 131,843 & 76,763 \\
\hline \multicolumn{7}{|c|}{ Men $>=45$} \\
\hline local linkage & $.109(.047)$ & $-.171(.046)$ & $.214(.051)$ & $-.269(.045)$ & $.156(.053)$ & $-.177(.051)$ \\
\hline $\mathrm{N}$ & 160,853 & 94,560 & 161,163 & 94,250 & 144,796 & 76,105 \\
\hline
\end{tabular}

Note: All models use twenty-five education categories - including non-tertiary general education, and include linear and quadratic effects of age, country fixed effects, level-field fixed effects, employment relationship effects, and detailed controls for educational level differences beyond what is captured in the level-field fixed effects.

We then add measures of the quality of the occupational match and an interaction between match quality and local linkage strength, and we graph in Figure 5 the effect of local linkage strength separately for well-matched workers (in blue) and less well-matched worker (in red) for both high-linkage and low-linkage countries as defined by our three grouping criteria. Row 1 presents results for the entire labor force and the next four rows present results separately by age-gender group. As with our earlier results, these estimates show that the earnings gap between well-matched and less-well-matched workers rises with local linkage strength, both in the entire sample and also in the age-gender subgroups. The results are similar in the high linkage and in the low linkage countries regardless of 
which grouping scheme we use. The principal difference visible in Figure 5 when we break the data down by age and gender group is that older men who are less well matched experience a growing penalty from stronger local linkage in low-linkage but not in high-linkage countries.

The six columns of Table 7 show the heterogeneity of total effects by high and low linkage strength countries across our three country grouping schemes by educational level and by gender. When focusing on the non-tertiary educated workers, we only see a positive total effect of local linkage for women in the high-linkage countries. In the low-linkage countries, the total effect of local linkage for non-tertiary educated workers is either zero or negative, depending on the grouping and which gender we focus on. In contrast, at the lower tertiary level the total effect is strongly positive in high linkage countries for both genders and in low linkage countries as well for women. At the upper-tertiary level, the estimate of total effects depends considerably on the grouping scheme in use.

When we look separately by education level at macro-structural effects, we get a rather complicated picture, mainly because the impact of macro-structure differs by gender at each education level (see Figure 6 and 7). Non-tertiary educated female workers who are well-matched benefit from stronger local linkage in high-linkage countries but not always in low-linkage countries (the low-linkage country results depend on whether we include the general-education non-tertiary workers in the calculation). However, we do not see a similar difference between local linkage effects in high-linkage and low-linkage countries for the male non-tertiary workers. For male lower-tertiary workers, both well-matched and less-well matched workers benefit more from local linkage in high-linkage than in lowlinkage countries. Women with lower-tertiary education, however, do not show a similar pattern. In contrast, female upper-tertiary workers who are well-matched benefit more from stronger local linkage in high- linkage countries than in low-linkage countries. However, there is not a similar pattern for men with upper-tertiary education.

Taken together, the evidence for macro-structural effects is suggestive, but not definitive. When we divide the countries into high-linkage and low-linkage countries (Table 5), we see stronger effects of local linkage in high-linkage than in low-linkage countries for both men and women. When we include country fixed effects and compare the effects of macro-structure in high-linkage and low-linkage countries by age-gender group, we find that men and older women have larger total effects of local linkage in high-linkage than in low-linkage countries, but the pattern differs for younger women. When we compare the effects of local linkage on relative wages for well-matched and less well-matched workers by educational level as well as country grouping, we find that one or the other gender has consistently higher effects of local linkage for well-matched workers in the high- 
linkage countries than in the low-linkage countries; however, the pattern breaks down for the other gender. We take this suggestive but mixed result to be a consequence of the fact that countries high in total linkage strength do not necessarily have high local linkage strength for every specific educational credentials. The within-country heterogeneity in the cross-country ranking of pathway strength may be the source of the complex pattern of macro-structure effects that emerges when we interrogate the data for subsets of a country's workforce defined by age, gender, or educational level. 


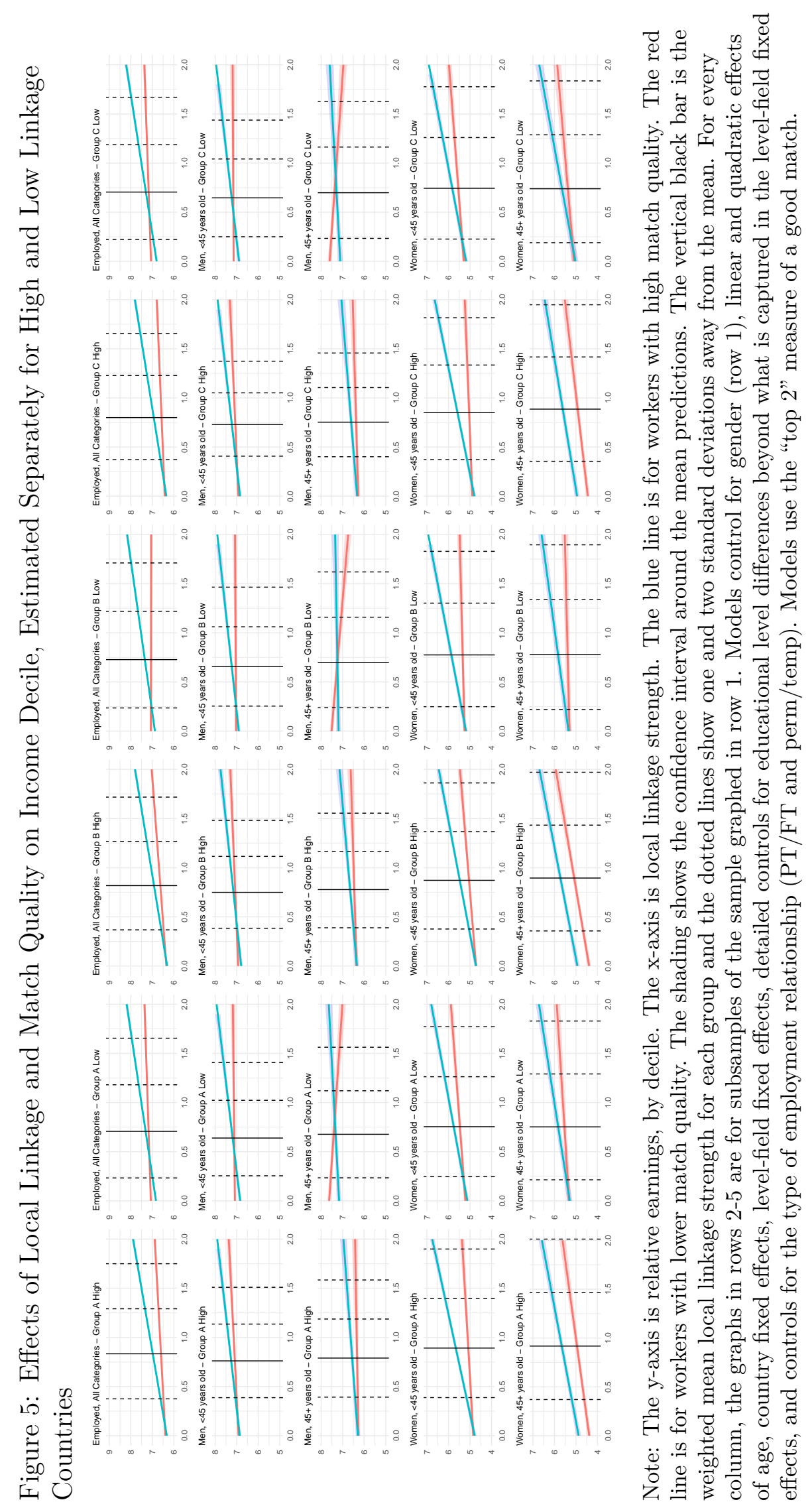


Table 7: Total Effects of Local Linkage on Net Earnings by Education Levels and Country Groups

\begin{tabular}{|c|c|c|c|c|c|c|}
\hline & \multicolumn{6}{|c|}{ Country Grouping Scheme } \\
\hline & \multicolumn{2}{|c|}{$\mathrm{A}$} & \multicolumn{2}{|c|}{$\mathrm{B}$} & \multicolumn{2}{|c|}{$\mathrm{C}$} \\
\hline & High & Low & High & Low & High & Low \\
\hline & \multicolumn{6}{|c|}{ Men } \\
\hline Non-Tertiary (Excl General) & $-.102(.064)$ & $-.281(.084)$ & $.012(.062)$ & $-.309(.080)$ & $-.114(.067)$ & $-.289(.096)$ \\
\hline $\mathrm{N}$ & 259,792 & 129,173 & 261,205 & 127,760 & 242,319 & 112,257 \\
\hline Non-Tertiary (Incl General) & $-.125(.058)$ & $-.292(.075)$ & $.043(.054)$ & $-.420(.073)$ & $-.093(.062)$ & $-.266(.088)$ \\
\hline $\mathrm{N}$ & 299,537 & 154,607 & 302,310 & 151,834 & 271,074 & 126,116 \\
\hline Lower Tertiary & $.479(.070)$ & $-.002(.071)$ & $.378(.063)$ & $-.050(.082)$ & $.481(.122)$ & $-.043(.081)$ \\
\hline $\mathrm{N}$ & 27,870 & 21,083 & 26,655 & 22,298 & 23,612 & 16,026 \\
\hline Upper Tertiary & $.058(.049)$ & $.230(.050)$ & $.007(.058)$ & $.008(.047)$ & $.104(.052)$ & $.128(.056)$ \\
\hline \multirow[t]{2}{*}{$\mathrm{N}$} & 77,101 & 63,540 & 78,891 & 61,750 & 69,525 & 51,945 \\
\hline & \multicolumn{6}{|c|}{ Women } \\
\hline Non-Tertiary (Excl General) & $.295(.050)$ & $-.038(.078)$ & $.481(.049)$ & $-.175(.076)$ & $.095(.051)$ & $-.331(.110)$ \\
\hline $\mathrm{N}$ & 204,192 & 106,126 & 208,118 & 102,200 & 193,663 & 87,390 \\
\hline Non-Tertiary (Incl General) & $.364(.044)$ & $.051(.065)$ & $.562(.042)$ & $-.201(.062)$ & $.187(.046)$ & $-.096(.094)$ \\
\hline $\mathrm{N}$ & 249,849 & 150,870 & 259,624 & 141,095 & 233,501 & 115,993 \\
\hline Lower Tertiary & $.439(.067)$ & $.796(.041)$ & $.569(.066)$ & $.717(.044)$ & $.209(.076)$ & $.864(.051)$ \\
\hline $\mathrm{N}$ & 26,797 & 34,539 & 29,709 & 31,627 & 26,236 & 23,361 \\
\hline Upper Tertiary & $-.180(.059)$ & $.197(.051)$ & $.186(.072)$ & $-.182(.047)$ & $.004(.062)$ & $.039(.060)$ \\
\hline $\mathrm{N}$ & 82,757 & 85,103 & 84,976 & 82,884 & 77,334 & 63,831 \\
\hline
\end{tabular}

Note: .All models include linear and quadratic effects of age, employment relationship, country fixed effects, level-field fixed effects, and detailed controls for educational level differences beyond what is captured in the level-field fixed effects. 


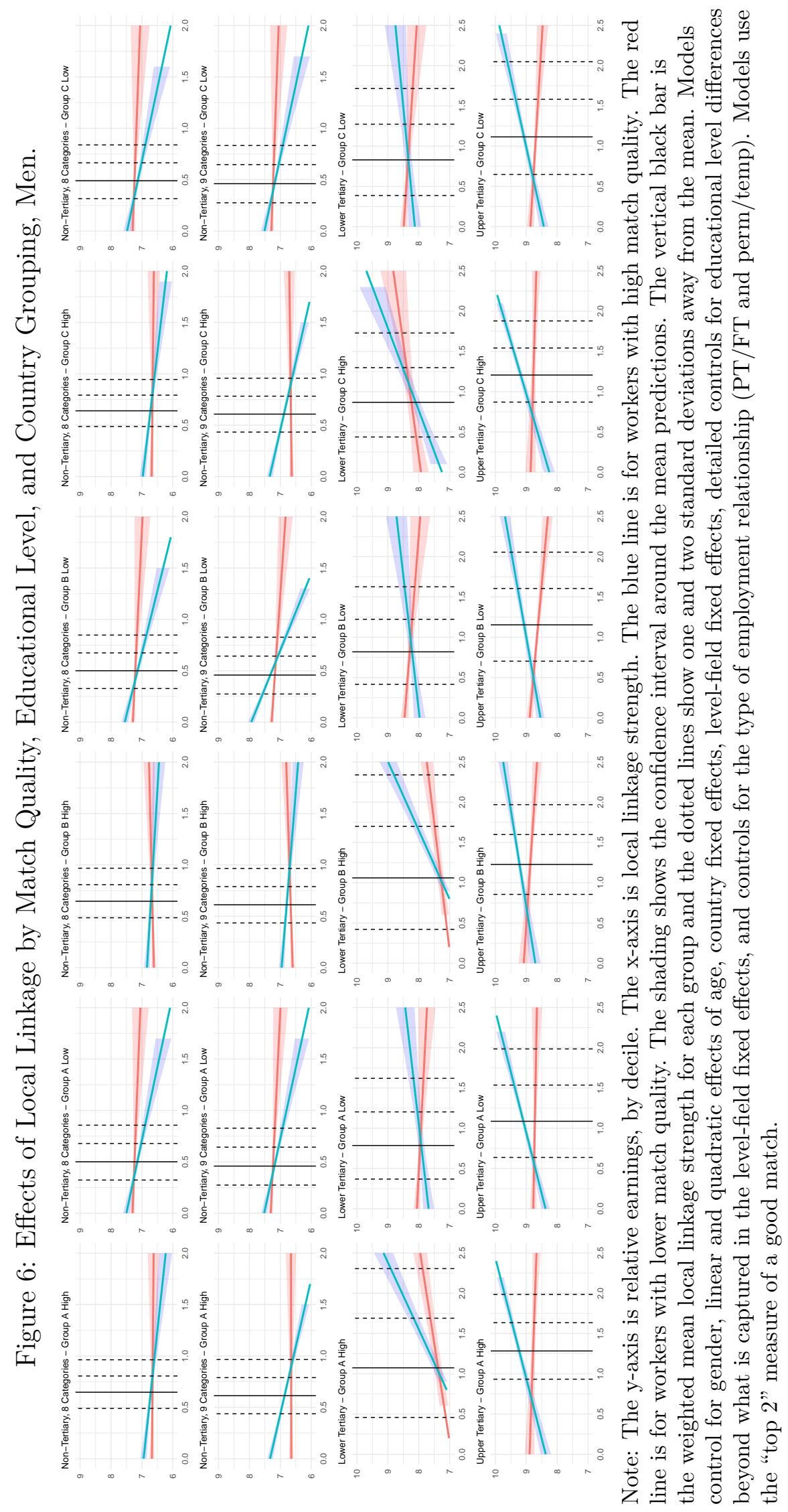




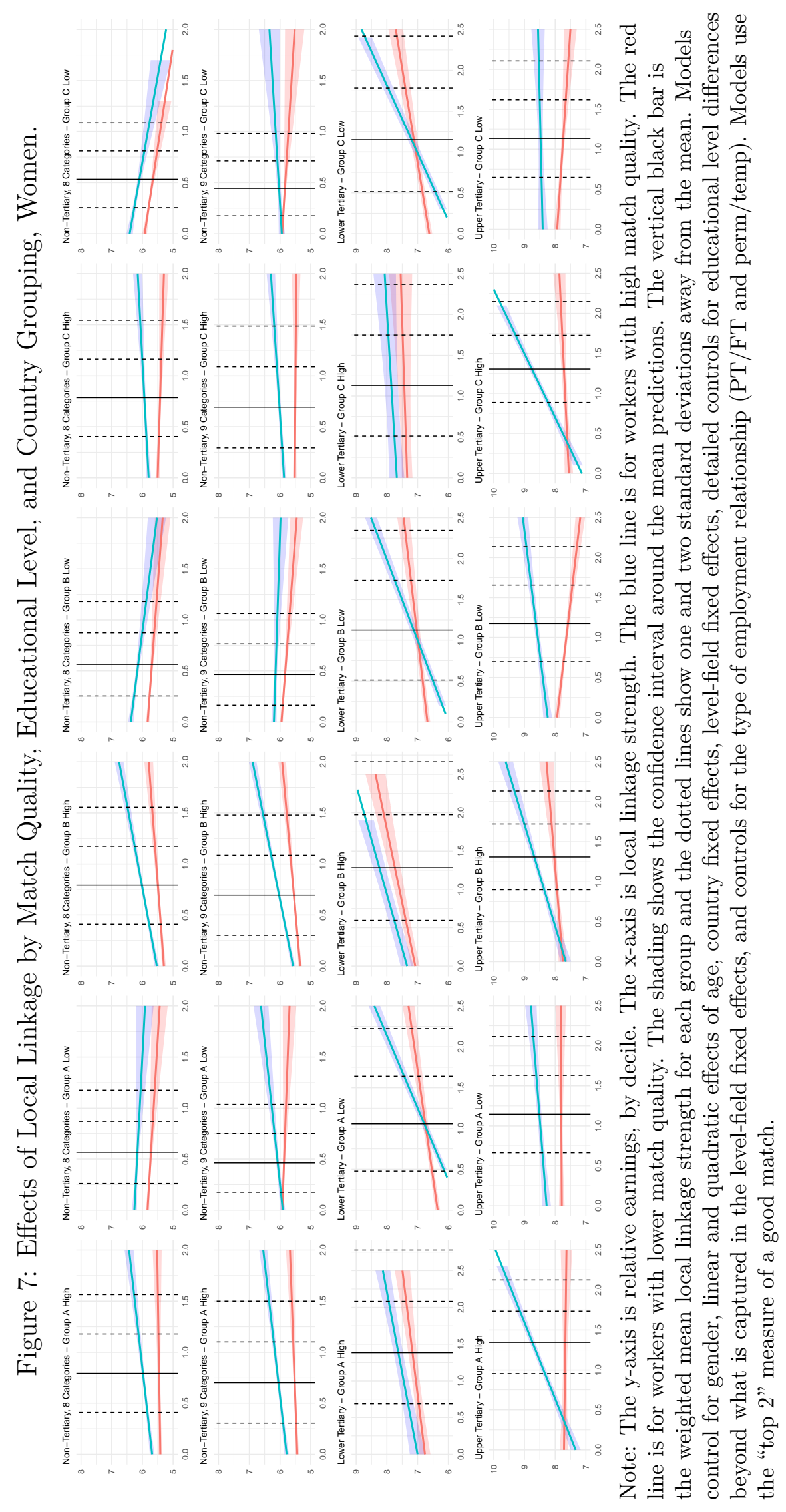




\subsection{Local Linkage Strength and Unemployment}

We combined the samples of workers who were either employed or unemployed in the EU LFS and estimated the strength of the relationship between local linkage strength and employment (see Table 8).26 For all four age-gender groups, the probability of employment increases (i.e., the probability of unemployment decreases) across the 21 countries for workers with the same educational credential when local linkage strength is greater. The effects are larger for younger female workers, but they clearly exist for all four age-gender groups. We then addressed the question whether local linkage effects on employment differed in high-linkage and low-linkage countries using the within-country-group/betweencountry strategy. As can be seen in Table 8, the effects were larger when comparing local linkage strength within the high linkage countries than within the low linkage countries.

Table 8: Effects of Local Linkage on the Probability of Employment, by Age-Gender Group and by Country Group.

\begin{tabular}{|c|c|c|c|}
\hline & \multicolumn{2}{|c|}{ b (s.e.) } & $\mathrm{N}$ \\
\hline Total & \multicolumn{2}{|c|}{$.016(.001)$} & $4,668,312$ \\
\hline Younger Women & \multicolumn{2}{|c|}{$.017(.001)$} & $1,373,061$ \\
\hline Younger Men & \multicolumn{2}{|c|}{$.008(.001)$} & $1,505,100$ \\
\hline Older Women & \multicolumn{2}{|c|}{$.005(.001)$} & 792,282 \\
\hline Older Men & \multicolumn{2}{|c|}{$.008(.001)$} & 997,869 \\
\hline & & \multicolumn{2}{|c|}{ Country Group } \\
\hline & & High & Low \\
\hline & Grouping A & $.019(.001)$ & $.007(.001)$ \\
\hline & $\mathrm{N}$ & $2,635,961$ & $2,032,351$ \\
\hline & Grouping B & $.020(.001)$ & $.007(.001)$ \\
\hline & $\mathrm{N}$ & $2,984,787$ & $1,683,525$ \\
\hline & Grouping C & $.013(.001)$ & $.006(.001)$ \\
\hline & $\mathrm{N}$ & $2,501,307$ & $1,445,213$ \\
\hline
\end{tabular}

Note: Samples include those who are currently employed or unemployed. Models include country fixed effects, level-field fixed effects, detailed country-specific level effects, linear and quadratic age effects and (in the models that distinguish high and low linkage countries) gender effects.

\section{Discussion}

An extensive body of research has long argued that the characteristics of a country's skill formation system affect both the performance of the national economy and the pattern

\footnotetext{
${ }^{26}$ Unemployment rates for each country from these data are shown in Table A.8.
} 
of labor market outcomes of a nation's workforce. This literature has persuasively illuminated important institutional differences across countries. Efforts to use the theoretical insights of these literatures to classify countries or to relate country differences to macro and micro outcomes have in some respects been quite successful, but there remain shortcomings as well. The theoretical schemes have not arrived at a stable classification for many countries, and many questions remain unanswered about whether and how institutional differences across countries matter for labor market outcomes. The linkage approach has argued that the ambiguity in classification arises in part from the failure to grasp that pathway structure - flowing from specific educational credentials to the occupations that are best matched to these credentials - is a more immediate determinant of labor market outcomes than is national institutional structure. While pathway structure is a consequence of national institutional structure, there is substantial heterogeneity in the relative ranking of pathway strength across countries due to the complexity of national institutions; this complexity resists a simple mapping from the country level to the level of specific pathways from educational credentials to occupations within a country. Earlier research has demonstrated in the context of a three country comparison that the strength of local linkage matters for both earnings and unemployment (Bol et al. 2019). This paper examines the effects of linkage across a much larger number of countries and provides a systematic examination of how countries differ in their linkage structure, whether these differences correspond to theoretical schemes for classifying skill formation systems, and whether the macro characteristics of a country's skill formation system matter for these outcomes.

Four findings stand out concerning the relationship between specific school to work pathways and labor market outcomes. First, stronger local linkage generally raises the relative earnings of workers with that credential relative to their counterparts in other countries. This pattern is quite evident in the results of Table 4. This positive total effect is largest at the lower-tertiary educational level with a smaller positive effect existing at the non-tertiary level. At the upper-tertiary level, the total effect of local linkage strength is positive or negative depending upon the age-group; this varying pattern stems from that fact that local linkage strength positively affects earnings only for the subset of uppertertiary workers who match well to their occupation. Second, stronger local linkage generally magnifies the earnings advantage of being in an occupation that matches well to one's educational credential relative to an occupation that matches less well. This effect - clearly in evidence for the population taken as a whole - is also generally found in the various subgroup analyses (including all age-gender groups) and also at all educational levels when attention is restricted to high-linkage countries. Third, one's probability of being 
employed, conditional on being in the labor force, is higher when local linkage strength is higher. Finally, the likelihood of being in a well-matched occupation is higher when local linkage strength for that educational credential is higher. This is not surprising but it bears repeating that strong pathways segregate workers into a narrower cluster of occupations; they therefore increase the proportion of workers with that credential who are in occupations that are well matched to their education and training.

A principal aim of this paper has been to establish the nature of macro-structural effects of a country's skill formation system on labor market outcomes. A country's macro characteristics matter in the first instance because of their impact on local linkage strength. The countries that were identified by the CASMIN and the VoC literatures as having the most clearly coordinated and qualificational skill formation systems do have relatively high total linkage strength, and (necessarily so) generally stronger local linkage for its educational credentials. Their generally stronger local linkage on the individual educational pathways implies higher relative earnings for workers in general, and, when we look more closely at subgroups, specifically for well matched workers at all three educational levels and even for not-well matched workers with a lower-tertiary degree. At the same time existing classification schemes do not well predict the location of many of the countries studied here in a ranking of total linkage strength. Our results should motivate a more careful institutional examination of countries that are near the extremes of the empirical ranking presented here but that have been understudied in the institutional literature.

This paper provides a strong empirical basis for ranking countries on the extent to which their skill formation systems lead to predictable occupational outcomes. Yet, the considerable and cross-country varying within-country heterogeneity in relative local linkage strength means that one cannot always accurately predict the local linkage strength of the 550 distinct pathways studied in this paper from a country's membership in the theoretical country clusters typically proposed in the literature. The tendency of scholars to focus on the few countries that best conform to theoretical schemes and, within these countries, to focus on those workers and those skills which best exemplify the institutional features of that country, is not an unreasonable approach. However, it makes the world seem more orderly at a macro-institutional level than in fact is the case. While countries can meaningfully be divided into high linkage and low linkage groups, this categorization hides considerable variation in local linkage strength within the same country.

We predicted that countries with high linkage strength and therefore generally more coherent educational pathways would also have higher penalties for not matching well because they would find it harder to get access to good jobs in non-matching occupations than would be the case for workers in low-linkage countries. We do not find consistent ev- 
idence supporting this prediction. When we focus on the total effects of local linkage, we find evidence of higher total effects of local linkage on earnings for male workers and for older female workers in high-linkage countries, but not younger female workers. We also find that total linkage strength of a country appears to reduce unemployment risk net of local linkage strength. Taken together, these results are suggestive that macro-structure matters over and above the effects of local linkage strength, but the pattern is not clear enough to be definitive.

The lack of pervasive and uniform macro-structural effects may stem in part from the ambiguity of establishing the membership in the categories of "high-linkage countries" and "low-linkage countries." As we have noted above, the literature sometimes achieves clarity by focusing on exemplar countries, but broader consensus is elusive. Even the ranking of an exemplar country like Germany is affected by whether one uses linkage strength driven partly by the occupational and educational marginal distributions, linkage strength adjusted for marginal distinctions, or measures computed from one or another age segment of the workforce, as shown in Appendix D. A bigger reason for the absence of clear macrostructural differences probably stems from the considerable internal heterogeneity in the relative rankings of pathway strength; in other words, the ranking of countries by the local linkage strength of specific credentials is not the same as the ranking of countries by total linkage strength. It is also possible that the variability in estimated macro effects by educational level is an artifact of the level of detail available in the EU LFS about fields of study. However, the demonstrative heterogeneity of pathway coherence within countries remains a prime hypothesis for why the evidence for country-level effects net of pathway effects is more suggestive than definitive.

The results presented above also provide additional confirmation for the conclusions in Bol et al. (2019). The only reliable way to assess the impact of different skill formation systems is to compare outcomes for workers in different countries who are leaving school with approximately the same skills. Bol et al. (2019) were able to compare outcomes for workers with non-tertiary credentials across two countries and were able to compare outcomes for workers with lower- or upper-tertiary credentials across three countries. The results in this paper compared outcomes for workers across 21 countries, and also across subsets of these countries defined in different ways to get at the distinction between high linkage and low linkage countries. Of course, these comparisons cannot be exact because fields of study is not standardized the same way in the educational systems in different nations. The analysis of EU LFS data involved a trade-off between the extent of differentiation in educational categories and the number of countries that could be studied. Nonetheless, the level of agreement in the results of the two studies provides important 
corroboration of the earlier results. They also justify efforts to collect comparable data about fields of study at higher levels of detail than are currently available. The greater the level of detail, the better one is able to study the workings of specific institutional connections between the skill formation system and the labor market.

An important message of this paper is that heterogeneity matters along multiple dimensions. Skill formation systems differ among countries in important ways. We have shown that key characteristics of these systems, namely the strength of local linkage and the quality of the match between credentials and occupations - affect labor market outcomes. Underneath this broadly consistent pattern are important differences that can be seen by comparing workers by age, or by gender, or by the level of their education, or by the overall linkage strength of their country, or even by specific fields of study within educational level, age group, and gender. Some of the differences in effects by age are probably driven by age-specific career processes, but others may reflect historical change. Elbers, Bol, and DiPrete (2021) demonstrated considerable change in the French skill formation system over a period of 40 years but less change in the German system. To disentangle these two sources of data over the broad set of countries studied here requires further improvements in available data even though the EU LFS data have provided a considerable advance in what we know. Additional data would enable improved specific policy recommendations as well as further advances in our understanding of the workings of skill formation systems.

The discussion of social policy in the skill formation literatures has generally focused on countries as the unit of analysis. This is sensible in that countries are the natural unit at which policies can be developed and implemented. At the same time, the consideration of country-level institutions as potential levers for social policy has also proved to be daunting because of the huge inertia possessed by macro-level institutions. Our results point to an alternative and potentially effective strategy for social policy. In many if not most countries, skill formation systems appear to be heterogeneous in their organization. In this sense, they are loosely structured. To the extent that high local linkage strength offers a career advantage, it would appear that the achievement of this policy goal need not require a complete transformation of a country's skill formation system. Rather, it can perhaps be accomplished one pathway at a time. How this might be possible depends upon the mechanisms that affect the linkage strength of pathways, and the extent to which these mechanisms operate at a national level or at the level of regional or local school districts and labor markets.

An important issue for policy concerns enhancing the benefits of local linkage for wellmatched workers while minimizing the penalty for not being well-matched. This could 
be challenging in some instances, because the general tendency for higher local linkage strength to increase the proportion of well-matched workers may be accompanied by increased penalties for those who fail to match well. This challenge is arguably addressable via the possibility of subsequent career job mobility. The impact of linkage on job mobility could not be addressed with the data available here; it is a topic for future research. Additional research into the multiple mechanisms that connect pathway structure to labor market outcomes would clarify feasible social policies as well as enhance our understanding about how skill formation systems shape the life chances of successive cohorts of workers. 


\section{A Appendix Tables}

Table A.1: Descriptive Statistics

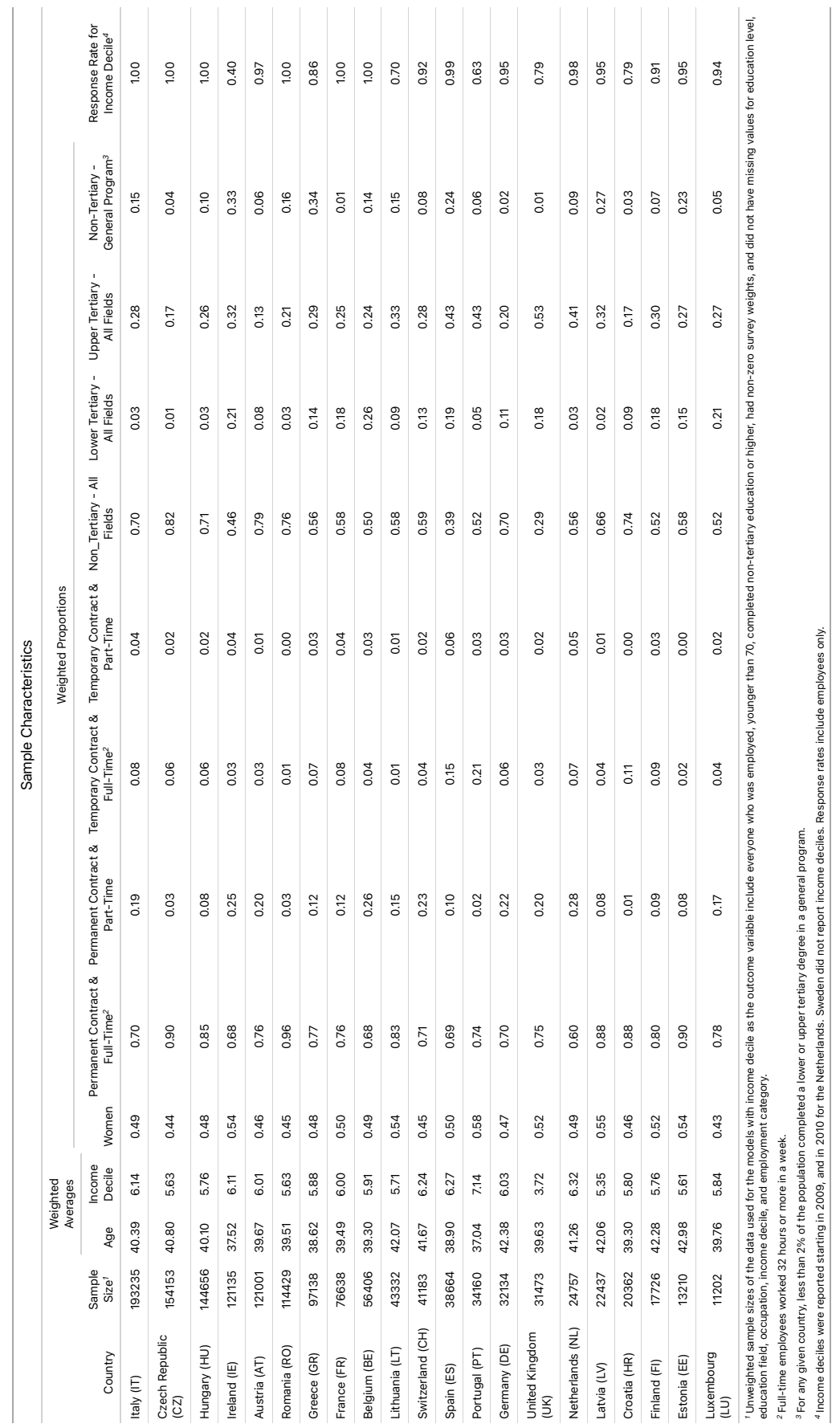


Table A.2: Occupational Quality Matches for the 25 Educational Levels and Fields of Study

\begin{tabular}{|c|c|c|c|}
\hline \multicolumn{4}{|c|}{ Top Occupations by Education } \\
\hline (ISCED 97) & Education Field & Top 1 Occupation (ISCO-88) & Top 2 Occupation (ISCO-88) \\
\hline 4 & General Programs & General Managers & Secretaries and keyboard-operating clerks \\
\hline 4 & $\begin{array}{l}\text { Education, Teacher } \\
\text { Training }\end{array}$ & $\begin{array}{l}\text { Pre-primary education teaching } \\
\text { associate professionals }\end{array}$ & Primary education teaching associate professionals \\
\hline 4 & $\begin{array}{l}\text { Humanities, Languages, } \\
\text { Arts }\end{array}$ & Printing and related trades workers & Artistic, entertainment and sports associate professionals \\
\hline 4 & $\begin{array}{l}\text { Social Sciences, } \\
\text { Business, Law }\end{array}$ & Numerical clerks & Customs, tax and related government associate professionals \\
\hline 4 & $\begin{array}{l}\text { Science, Math, Computer } \\
\text { Science }\end{array}$ & Computing professionals & Computer associate professionals \\
\hline 4 & $\begin{array}{l}\text { Engineering, Manuf., } \\
\text { Construction }\end{array}$ & $\begin{array}{l}\text { Blacksmiths, tool-makers and related } \\
\text { trades workers }\end{array}$ & $\begin{array}{l}\text { Metal moulders, welders, sheet-metal workers, structural-metal } \\
\text { preparers, and related trades workers }\end{array}$ \\
\hline 4 & Agriculture, Veterinary & $\begin{array}{l}\text { Market-oriented skilled agricultural and } \\
\text { fishery workers }\end{array}$ & Market-oriented animal producers and related workers \\
\hline 4 & Health and Welfare & $\begin{array}{l}\text { Nursing and midwifery associate } \\
\text { professionals }\end{array}$ & Modern health associate professionals (except nursing) \\
\hline 4 & Services & Other personal services workers & Housekeeping and restaurant services workers \\
\hline 5 & $\begin{array}{l}\text { Education, Teacher } \\
\text { Training }\end{array}$ & $\begin{array}{l}\text { Pre-primary education teaching } \\
\text { associate professionals }\end{array}$ & Primary and pre-primary education teaching professionals \\
\hline 5 & $\begin{array}{l}\text { Humanities, Languages, } \\
\text { Arts }\end{array}$ & $\begin{array}{l}\text { Writers and creative or performing } \\
\text { artists }\end{array}$ & Artistic, entertainment and sports associate professionals \\
\hline 5 & $\begin{array}{l}\text { Social Sciences, } \\
\text { Business, Law }\end{array}$ & Office clerks & Administrative associate professionals \\
\hline 5 & $\begin{array}{l}\text { Science, Math, Computer } \\
\text { Science }\end{array}$ & Computer associate professionals & Computing professionals \\
\hline 5 & $\begin{array}{l}\text { Engineering, Manuf., } \\
\text { Construction }\end{array}$ & $\begin{array}{l}\text { Building finishers and related trades } \\
\text { workers }\end{array}$ & Machinery mechanics and fitters \\
\hline 5 & Agriculture, Veterinary & $\begin{array}{l}\text { Market-oriented skilled agricultural and } \\
\text { fishery workers }\end{array}$ & Market-oriented crop and animal producers \\
\hline 5 & Health and Welfare & $\begin{array}{l}\text { Nursing and midwifery associate } \\
\text { professionals }\end{array}$ & Nursing and midwifery professionals \\
\hline 5 & Services & Other personal services workers & Police inspectors and detectives \\
\hline 6 & $\begin{array}{l}\text { Education, Teacher } \\
\text { Training }\end{array}$ & $\begin{array}{l}\text { Special education teaching } \\
\text { professionals }\end{array}$ & Primary and pre-primary education teaching professionals \\
\hline 6 & $\begin{array}{l}\text { Humanities, Languages, } \\
\text { Arts }\end{array}$ & $\begin{array}{l}\text { Writers and creative or performing } \\
\text { artists }\end{array}$ & Artistic, entertainment and sports associate professionals \\
\hline 6 & $\begin{array}{l}\text { Social Sciences, } \\
\text { Business, Law }\end{array}$ & Legal professionals & Business professionals \\
\hline 6 & $\begin{array}{l}\text { Science, Math, Computer } \\
\text { Science }\end{array}$ & $\begin{array}{l}\text { Physicists, chemists, and related } \\
\text { professionals }\end{array}$ & Computing professionals \\
\hline 6 & $\begin{array}{l}\text { Engineering, Manuf., } \\
\text { Construction }\end{array}$ & $\begin{array}{l}\text { Architects, engineers and related } \\
\text { professionals }\end{array}$ & Physical and engineering science technicians \\
\hline 6 & Agriculture, Veterinary & Life science professionals & Market gardeners and crop growers \\
\hline 6 & Health and Welfare & $\begin{array}{l}\text { Nursing and midwifery associate } \\
\text { professionals }\end{array}$ & Health professionals (except nursing) \\
\hline 6 & Services & $\begin{array}{l}\text { Ship and aircraft controllers and } \\
\text { technicians }\end{array}$ & Armed forces \\
\hline
\end{tabular}




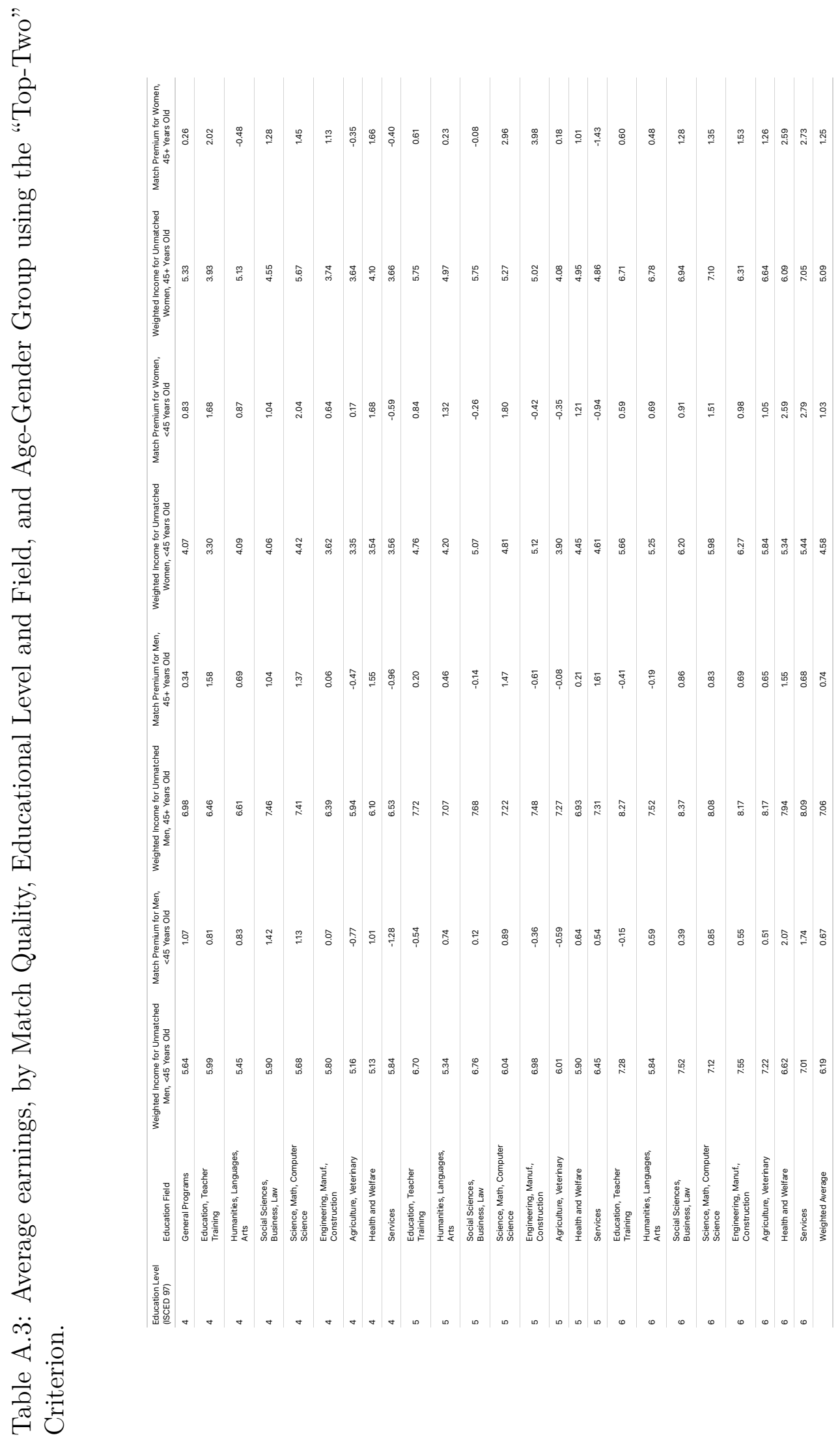


Table A.4: Percent of Workers in Well-Matched Occupations, Mean Rank, and (from Koumenta and Pagliero (2017)), the Proportions Licensed and Certified, by Country

\begin{tabular}{|c|c|c|c|c|c|}
\hline country & Top $2(\%)$ & Top $3(\%)$ & Mean Rank & Licensed (\%) & Certified (\%) \\
\hline Greece & 28.7 & 38.5 & 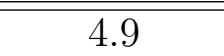 & $\overline{222}$ & $\overline{12}$ \\
\hline Luxembourg & 30.2 & 36.3 & 5.0 & 21 & 21 \\
\hline Finland & 19.2 & 32.1 & 4.5 & 17 & 9 \\
\hline Germany & 21.1 & 29.3 & 4.3 & 33 & 36 \\
\hline Croatia & 23.9 & 28.3 & 4.3 & 31 & 14 \\
\hline Switzerland & 18.1 & 24.6 & 3.9 & - & - \\
\hline Czech Rep & 20.3 & 24.0 & 3.5 & 25 & 16 \\
\hline Hungary & 21.7 & 26.4 & 3.8 & 26 & 22 \\
\hline Austria & 15.6 & 20.7 & 3.8 & 22 & 24 \\
\hline Romania & 21.1 & 25.5 & 3.7 & 22 & 26 \\
\hline Spain & 24.7 & 33.6 & 4.4 & 17 & 21 \\
\hline Lithuania & 16.2 & 21.7 & 3.4 & 18 & 26 \\
\hline Estonia & 15.5 & 20.6 & 3.2 & 19 & 18 \\
\hline Latvia & 18.4 & 22.9 & 3.3 & 15 & 22 \\
\hline Belgium & 14.5 & 23.6 & 3.8 & 17 & 15 \\
\hline Portugal & 18.5 & 28.1 & 4.4 & 17 & 12 \\
\hline Ireland & 18.3 & 27.6 & 4.1 & 29 & 21 \\
\hline France & 12.6 & 19.1 & 3.2 & 17 & 15 \\
\hline UK & 15.7 & 24.6 & 3.8 & 19 & 20 \\
\hline Netherlands & 21.2 & 27.6 & 3.9 & 25 & 24 \\
\hline Italy & 15.9 & 21.3 & 3.4 & 19 & 12 \\
\hline
\end{tabular}

Note: In computing rank, the top ranked occupation by the matching criterion is scored 10 , the next occupation 9 and so forth for the ten most common occupational destinations for each level-field. Occupations outside the top ten are scored zero. 
Table A.5: Occupational Quality Matches for the 25 Educational Levels and Fields of Study, Females Only

\begin{tabular}{|c|c|c|c|}
\hline \multicolumn{4}{|c|}{ Top Occupations by Education for Women } \\
\hline Education Level (ISCED & & & \\
\hline 97) & Education Field & Top 1 Occupation (ISCO-88) & Top 2 Occupation (ISCO-88) \\
\hline 4 & General Programs & Primary education teaching associate professionals & $\begin{array}{l}\text { Domestic and related helpers, cleaners and } \\
\text { launderers }\end{array}$ \\
\hline 4 & Education, Teacher Training & $\begin{array}{l}\text { Pre-primary education teaching associate } \\
\text { professionals }\end{array}$ & $\begin{array}{l}\text { Primary education teaching associate } \\
\text { professionals }\end{array}$ \\
\hline 4 & Humanities, Languages, Arts & $\begin{array}{l}\text { Artistic, entertainment and sports associate } \\
\text { professionals }\end{array}$ & Market gardeners and crop growers \\
\hline 4 & $\begin{array}{l}\text { Social Sciences, Business, } \\
\text { Law }\end{array}$ & $\begin{array}{l}\text { Customs, tax and related government associate } \\
\text { professionals }\end{array}$ & Numerical clerks \\
\hline 4 & $\begin{array}{l}\text { Science, Math, Computer } \\
\text { Science }\end{array}$ & Computer associate professionals & Physical and engineering science technicians \\
\hline 4 & $\begin{array}{l}\text { Engineering, Manuf., } \\
\text { Construction }\end{array}$ & Textile, garment and related trades workers & $\begin{array}{l}\text { Textile-, fur- and leather-products machine } \\
\text { operators }\end{array}$ \\
\hline 4 & Agriculture, Veterinary & Animal producers and related workers & Market gardeners and crop growers \\
\hline 4 & Health and Welfare & Nursing and midwifery associate professionals & Health associate professionals (except nursing) \\
\hline 4 & Services & Other personal services workers & Housekeeping and restaurant services workers \\
\hline 5 & Education, Teacher Training & $\begin{array}{l}\text { Pre-primary education teaching associate } \\
\text { professionals }\end{array}$ & $\begin{array}{l}\text { Primary and pre-primary education teaching } \\
\text { professionals }\end{array}$ \\
\hline 5 & Humanities, Languages, Arts & $\begin{array}{l}\text { Artistic, entertainment and sports associate } \\
\text { professionals }\end{array}$ & Writers and creative or performing artists \\
\hline 5 & $\begin{array}{l}\text { Social Sciences, Business, } \\
\text { Law }\end{array}$ & Office clerks & Administrative associate professionals \\
\hline 5 & $\begin{array}{l}\text { Science, Math, Computer } \\
\text { Science }\end{array}$ & Computer associate professionals & Computing professionals \\
\hline 5 & $\begin{array}{l}\text { Engineering, Manuf., } \\
\text { Construction }\end{array}$ & Physical and engineering science technicians & Architects, engineers and related professionals \\
\hline 5 & Agriculture, Veterinary & Market gardeners and crop growers & $\begin{array}{l}\text { Life science technicians and related associate } \\
\text { professionals }\end{array}$ \\
\hline 5 & Health and Welfare & Nursing and midwifery associate professionals & Nursing and midwifery professionals \\
\hline 5 & Services & Other personal services workers & Housekeeping and restaurant services workers \\
\hline 6 & Education, Teacher Training & Special education teaching professionals & $\begin{array}{l}\text { Primary and pre-primary education teaching } \\
\text { professionals }\end{array}$ \\
\hline 6 & Humanities, Languages, Arts & Writers and creative or performing artists & Secondary education teaching professionals \\
\hline 6 & $\begin{array}{l}\text { Social Sciences, Business, } \\
\text { Law }\end{array}$ & Legal professionals & Business professionals \\
\hline 6 & $\begin{array}{l}\text { Science, Math, Computer } \\
\text { Science }\end{array}$ & Physicists, chemists and related professionals & Life science professionals \\
\hline 6 & $\begin{array}{l}\text { Engineering, Manuf., } \\
\text { Construction }\end{array}$ & Architects, engineers and related professionals & Physical and engineering science technicians \\
\hline 6 & Agriculture, Veterinary & Life science professionals & Health professionals (except nursing) \\
\hline 6 & Health and Welfare & Nursing and midwifery professionals & Health professionals (except nursing) \\
\hline 6 & Services & Client information clerks & Finance and sales associate professionals \\
\hline
\end{tabular}


Table A.6: Occupational Quality Matches for the 25 Educational Levels and Fields of Study, Males Only

\begin{tabular}{|c|c|c|c|}
\hline & & Top Occupations by Education for Men & \\
\hline $\begin{array}{l}\text { Education Level (ISCED } \\
\text { 97) }\end{array}$ & Education Field & Top 1 Occupation (ISCO-88) & Top 2 Occupation (ISCO-88) \\
\hline 4 & General Programs & Protective services workers & Other office clerks \\
\hline 4 & Education, Teacher Training & $\begin{array}{l}\text { Pre-primary education teaching associate } \\
\text { professionals }\end{array}$ & Primary education teaching associate \\
\hline 4 & Humanities, Languages, Arts & Craft printing and related trades workers & $\begin{array}{l}\text { Artistic, entertainment and sports associate } \\
\text { professionals }\end{array}$ \\
\hline 4 & $\begin{array}{l}\text { Social Sciences, Business, } \\
\text { Law }\end{array}$ & Numerical clerks & $\begin{array}{l}\text { Customs, tax and related government associate } \\
\text { professionals }\end{array}$ \\
\hline 4 & $\begin{array}{l}\text { Science, Math, Computer } \\
\text { Science }\end{array}$ & Computing professionals & Computer associate professionals \\
\hline 4 & $\begin{array}{l}\text { Engineering, Manuf., } \\
\text { Construction }\end{array}$ & $\begin{array}{l}\text { Blacksmiths, tool-makers and related trades } \\
\text { workers }\end{array}$ & Machinery mechanics and fitters \\
\hline 4 & Agriculture, Veterinary & Market gardeners and crop growers & Animal producers and related workers \\
\hline 4 & Health and Welfare & Nursing and midwifery associate professionals & Health associate professionals (except nursing) \\
\hline 4 & Services & Housekeeping and restaurant services workers & Locomotive engine drivers and related workers \\
\hline 5 & Education, Teacher Training & $\begin{array}{l}\text { Pre-primary education teaching associate } \\
\text { professionals }\end{array}$ & $\begin{array}{l}\text { Primary and pre-primary education teaching } \\
\text { professionals }\end{array}$ \\
\hline 5 & Humanities, Languages, Arts & Craft printing and related trades workers & Writers and creative or performing artists \\
\hline 5 & $\begin{array}{l}\text { Social Sciences, Business, } \\
\text { Law }\end{array}$ & Numerical clerks & Public service administrative professionals \\
\hline 5 & $\begin{array}{l}\text { Science, Math, Computer } \\
\text { Science }\end{array}$ & Computer associate professionals & Computing professionals \\
\hline 5 & $\begin{array}{l}\text { Engineering, Manuf., } \\
\text { Construction }\end{array}$ & Building finishers and related trades workers & Machinery mechanics and fitters \\
\hline 5 & Agriculture, Veterinary & Crop and animal producers & Market gardeners and crop growers \\
\hline 5 & Health and Welfare & Nursing and midwifery associate professionals & Nursing and midwifery professionals \\
\hline 5 & Services & Ship and aircraft controllers and technicians & Police inspectors and detectives \\
\hline 6 & Education, Teacher Training & Special education teaching professionals & $\begin{array}{l}\text { Primary and pre-primary education teaching } \\
\text { professionals }\end{array}$ \\
\hline 6 & Humanities, Languages, Arts & Religious professionals & Writers and creative or performing artists \\
\hline 6 & $\begin{array}{l}\text { Social Sciences, Business, } \\
\text { Law }\end{array}$ & Legal professionals & Administrative associate professionals \\
\hline 6 & $\begin{array}{l}\text { Science, Math, Computer } \\
\text { Science }\end{array}$ & Physicists, chemists and related professionals & Computing professionals \\
\hline 6 & $\begin{array}{l}\text { Engineering, Manuf., } \\
\text { Construction }\end{array}$ & Architects, engineers and related professionals & Physical and engineering science technicians \\
\hline 6 & Agriculture, Veterinary & Life science professionals & $\begin{array}{l}\text { Life science technicians and related associate } \\
\text { professionals }\end{array}$ \\
\hline 6 & Health and Welfare & Health professionals (except nursing) & Nursing and midwifery professionals \\
\hline 6 & Services & Ship and aircraft controllers and technicians & Legislators and senior officials \\
\hline
\end{tabular}




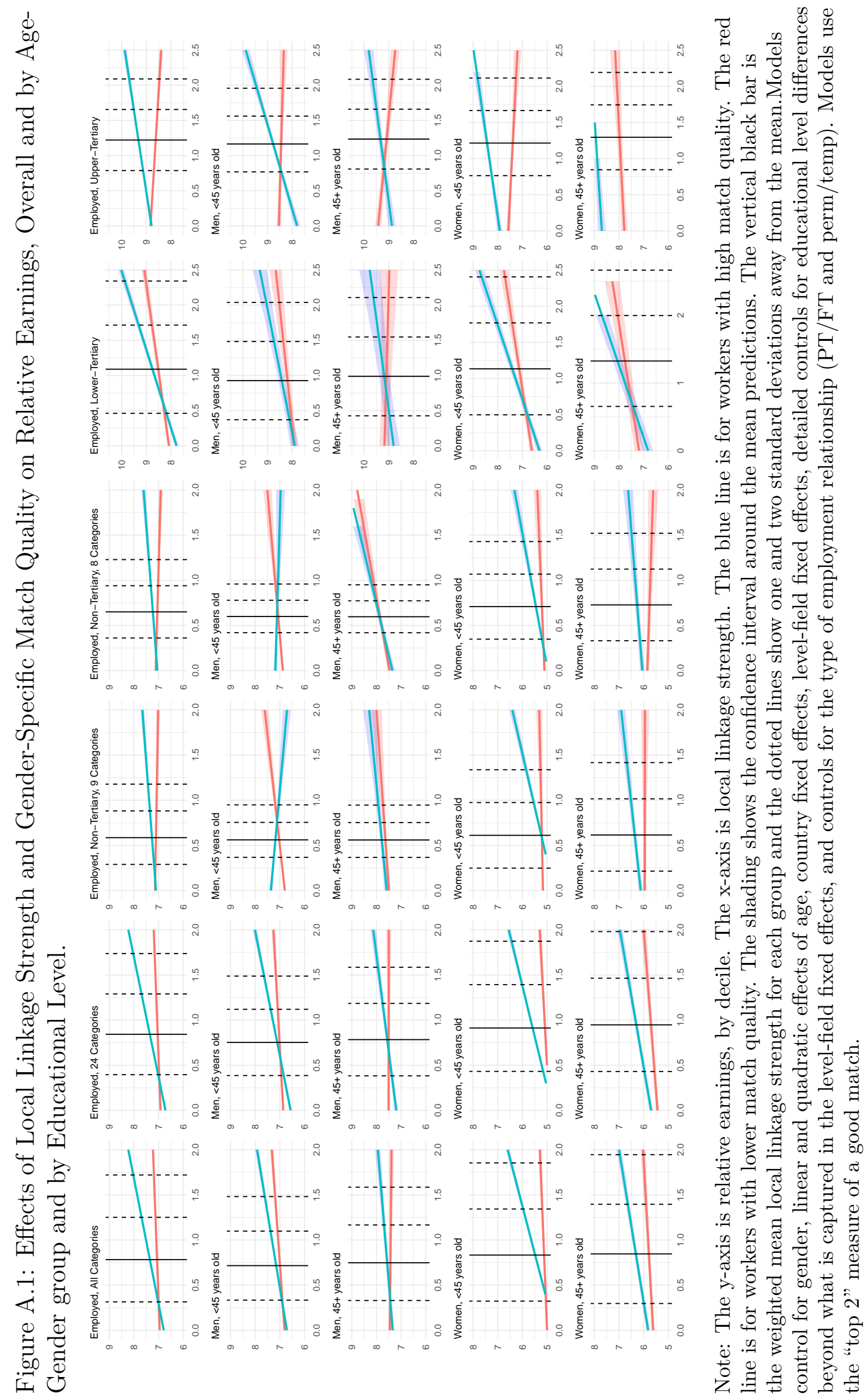


Table A.7: Effects of Local Linkage and Match Quality on Net Earnings for Country Groups: By Education Levels

\begin{tabular}{|c|c|c|c|c|c|c|}
\hline & \multicolumn{6}{|c|}{ Country Grouping Scheme } \\
\hline & \multicolumn{2}{|c|}{$\mathrm{A}$} & \multicolumn{2}{|c|}{ B } & \multicolumn{2}{|c|}{$\mathrm{C}$} \\
\hline & High & Low & High & Low & High & Low \\
\hline \multirow[b]{2}{*}{ linkage } & \multicolumn{6}{|c|}{ Non Tertiary, Excluding General Education } \\
\hline & $-.136(.040)$ & $-.391(.058)$ & $-.008(.039)$ & $-.585(.055)$ & $-.225(.041)$ & $-.531(.073)$ \\
\hline match & $-.009(.021)$ & $.302(.031)$ & $-.031(.021)$ & $.419(.033)$ & $.020(.022)$ & $.346(.034)$ \\
\hline linkage*match & $.392(.023)$ & $-.226(.046)$ & $.417(.023)$ & $-.421(.050)$ & $.350(.024)$ & $-.327(.051)$ \\
\hline \multirow[t]{2}{*}{ Sample Size } & 463,984 & 235,299 & 469,323 & 229,960 & 435,982 & 199,647 \\
\hline & \multicolumn{6}{|c|}{ Non Tertiary, Including General Education } \\
\hline linkage & $-.060(.036)$ & $-.362(.050)$ & $.069(.034)$ & $-.555(.047)$ & $-.142(.038)$ & $-.389(.065)$ \\
\hline match & $.209(.019)$ & $.045(.029)$ & $.026(.019)$ & $.410(.030)$ & $.231(.020)$ & $.087(.033)$ \\
\hline linkage*match & $.198(.021)$ & $.019(.044)$ & $.371(.021)$ & $-.441(.048)$ & $.164(.022)$ & $-.080(.050)$ \\
\hline \multirow[t]{2}{*}{ Sample Size } & 549,386 & 305,477 & 561,934 & 292,929 & 504,575 & 242,109 \\
\hline & \multicolumn{6}{|c|}{ Lower Tertiary } \\
\hline linkage & $.319(.047)$ & $.149(.038)$ & $.341(.044)$ & $.157(.042)$ & $.190(.065)$ & $.158(.045)$ \\
\hline match & $-.478(.058)$ & $-.714(.045)$ & $-.528(.058)$ & $-.626(.047)$ & $-.386(.062)$ & $-.756(.052)$ \\
\hline linkage*match & $.546(.042)$ & $.717(.030)$ & $.623(.040)$ & $.661(.034)$ & $.444(.047)$ & $.735(.035)$ \\
\hline \multirow[t]{2}{*}{ Sample Size } & 54,667 & 55,622 & 56,364 & 53,925 & 49,848 & 39,387 \\
\hline & \multicolumn{6}{|c|}{ Upper Tertiary } \\
\hline linkage & $-.277(.038)$ & $-.058(.036)$ & $-.068(.045)$ & $-.373(.033)$ & $-.162(.040)$ & $-.197(.041)$ \\
\hline match & $-.670(.045)$ & $-.117(.040)$ & $-.348(.041)$ & $-.214(.043)$ & $-.751(.047)$ & $-.164(.045)$ \\
\hline linkage*match & $1.064(.031)$ & $.538(.030)$ & $.638(.030)$ & $.788(.031)$ & $1.144(.033)$ & $.583(.034)$ \\
\hline Sample Size & 159,858 & 148,643 & 163,867 & 144,634 & 146,859 & 115,776 \\
\hline
\end{tabular}

Note: All models also include linear and quadratic effects of gender, linear and quadratic effects of age, employment relationship, country fixed effects, level-field fixed effects, and detailed controls for educational level differences beyond what is captured in the level-field fixed effects. Match quality is measured using the "top two" criterion. 
Table A.8: Unemployment Rates by Country

\begin{tabular}{lc}
\hline Unemployment Rates by Country \\
\hline Country & Unemployment Rate \\
\hline Austria & 0.0372 \\
\hline Belgium & 0.0556 \\
\hline Switzerland & 0.0320 \\
\hline Czech Republic & 0.0500 \\
\hline Germany & 0.0676 \\
\hline Estonia & 0.0813 \\
\hline Spain & 0.0930 \\
\hline Finland & 0.0567 \\
\hline France & 0.0665 \\
\hline Greece & 0.0950 \\
\hline Croatia & 0.0951 \\
\hline Hungary & 0.0691 \\
\hline Ireland & 0.0757 \\
\hline Italy & 0.0579 \\
\hline Lithuania & 0.0882 \\
\hline Luxembourg & 0.0384 \\
\hline Latvia & 0.1030 \\
\hline Netherlands & 0.0272 \\
\hline Portugal & 0.0775 \\
\hline Romania & 0.0649 \\
\hline Sweden & 0.0492 \\
\hline United Kingdom & 0.0413 \\
\hline
\end{tabular}




\section{B Country Variation in Local Linkage Strength by Educational Credential}

Table B.1 reports the unadjusted and margins-adjusted local linkage scores and the unadjusted and margins-adjusted coefficient of variation (CV, equal to the standard deviation divided by the mean) for the workforce. Reporting both unadjusted and adjusted scores allows one to see the extent to which variation in local linkage strength across countries and within specific level-fields is or is not affected by country variation in the occupational distribution.

Table B.1 makes clear that the average - across all countries - local linkage strength varies across the level-fields. It also shows that the extent of variation across countries within a level-field also varies across the level-fields. Local linkage strength is higher at the tertiary level than it is at the non-tertiary level. At the non-tertiary level, local linkage strength is especially low among those workers who report having a general education. For all educational levels, the extent of country-level variation is considerable. However, when one looks at specific fields, one sees large differences in the extent of country variation. At one extreme, Table B.1 provides evidence for the widespread and relatively uniform professionalization of the health fields at the upper-tertiary level. This is apparent in their very high local linkage strength (the highest of the 25 level-fields) and also in their low variation across countries. Indeed, when country differences in marginal distributions are taken into account, upper-tertiary health and welfare fields show the lowest variation - as measured by the CV - of any of the 25 level-fields.

The existing literature on comparative educational systems generally focuses most attention on the organization of non-tertiary level vocational training as a key source of differentiation across countries (Shavit and Müller 1998; Hanushek et al. 2017). That work emphasizes compositional differences in countries reflected in the proportion of nontertiary workers who receive only general education. Table B.1, in contrast, addresses the extent to which the pathways leading from specific fields of study vary in strength across countries. The relatively high variability at the two lower educational levels might be taken as evidence of the importance of vocationally organized educational systems as an important dimension of variation across countries (Shavit and Müller 1998), but, if so, it suggests that variation in the organization of vocational education has spread to the lowertertiary level of education.

As Elbers, Bol, and DiPrete (2021) showed, the theoretical distinction between organizational and credential spaces in Maurice, Sellier, and Silvestre (1986), which asserts a large difference between the pathway structure of France and Germany, turned out to 
Table B.1: Variation by Country in Local Linkage Strength of Specific Educational Credentials, Unadjusted and Margins-Adjusted Data

\begin{tabular}{|c|c|c|c|c|c|}
\hline Level & Field & $\begin{array}{l}\text { Mean } \\
\text { unadj }\end{array}$ & $\begin{array}{c}\text { Mean } \\
\text { adj }\end{array}$ & $\begin{array}{c}\mathrm{CV} \\
\text { unadj }\end{array}$ & $\begin{array}{l}\mathrm{CV} \\
\operatorname{adj}\end{array}$ \\
\hline \multirow[t]{9}{*}{ Non Tertiary } & General Education & 0.30 & 0.32 & 0.45 & 0.35 \\
\hline & Education, Teacher Training & 1.60 & 1.60 & 0.56 & 0.43 \\
\hline & Humanities, Languages, Arts & 0.76 & 0.72 & 0.40 & 0.33 \\
\hline & Social Sciences, Business, Law & 0.53 & 0.50 & 0.26 & 0.21 \\
\hline & Science, Math, Comp Sci & 0.66 & 0.70 & 0.48 & 0.45 \\
\hline & Engineer, Manuf, Construction & 0.60 & 0.57 & 0.47 & 0.15 \\
\hline & Agriculture, Veterinary & 1.14 & 1.17 & 0.51 & 0.35 \\
\hline & Health and Welfare & 1.56 & 1.37 & 0.30 & 0.25 \\
\hline & Services & 0.75 & 0.76 & 0.33 & 0.17 \\
\hline \multirow[t]{8}{*}{ Lower Tertiary } & Education, Teacher Training & 1.81 & 1.79 & 0.33 & 0.32 \\
\hline & Humanities, Languages, Arts & 1.28 & 1.23 & 0.43 & 0.32 \\
\hline & Social Sciences, Business, Law & 0.68 & 0.67 & 0.36 & 0.30 \\
\hline & Science, Math, Comp Sci & 1.23 & 1.24 & 0.42 & 0.36 \\
\hline & Engineer, Manuf, Construction & 0.78 & 0.74 & 0.41 & 0.31 \\
\hline & Agriculture, Veterinary & 1.42 & 1.59 & 0.38 & 0.24 \\
\hline & Health and Welfare & 1.81 & 1.64 & 0.26 & 0.24 \\
\hline & Services & 1.14 & 1.10 & 0.49 & 0.43 \\
\hline \multirow[t]{8}{*}{ Upper Tertiary } & Education, Teacher Training & 1.73 & 1.64 & 0.25 & 0.13 \\
\hline & Humanities, Languages, Arts & 1.19 & 1.04 & 0.42 & 0.25 \\
\hline & Social Sciences, Business, Law & 0.93 & 0.86 & 0.38 & 0.19 \\
\hline & Science, Math, Comp Sci & 1.22 & 1.18 & 0.35 & 0.25 \\
\hline & Engineer, Manuf, Construction & 1.28 & 1.26 & 0.34 & 0.28 \\
\hline & Agriculture, Veterinary & 1.29 & 1.27 & 0.35 & 0.27 \\
\hline & Health and Welfare & 2.24 & 1.93 & 0.29 & 0.10 \\
\hline & Services & 0.93 & 0.97 & 0.37 & 0.28 \\
\hline
\end{tabular}

largely be a story about the greater proportion of Germany non-tertiary workers who received a vocational education, not a story about stronger connectivity between these vocational credentials and specific occupational placement. A similar pattern may be at work in Table B.1; the relatively high variability in linkage for workers with non-tertiary engineering/manufacturing/construction training appears mostly to be a story about country differences in the educational and occupational distribution.

Table B.1 also shows what appear to be true structural differences across countries in the organization of certain fields, such as education/teacher training at the secondary level, science/math/computer science training at the secondary or lower-tertiary levels, or services at the lower-tertiary level. Education and teacher training illustrates perhaps 
most clearly the variation in the organization of educational systems across countries. When we focus at the upper-tertiary level (where professionalized educational training is nearly universal), we find little variation in local linkage strength, especially when differences in marginal distributions are taken into account. At the non-tertiary level, in contrast, we see large differences in local linkage strength in education/teacher training by country, which suggests that sub-professional training in education is organized very differently across countries.

\section{How Similar is Linkage Strength Across Levels?}

As we discussed earlier in this paper, the literature on skill formation systems has found it difficult to produce a theoretically unified perspective across the different levels of the educational system. This would be more surprising if countries with tight linkage at lower educational levels also had tight linkage at the upper-tertiary level. It would be less surprising if total linkage strength at one level is a poor predictor of total linkage strength at a different level. To address this question, we computed linkage strength separately for workers with upper-tertiary education and for workers with non-tertiary or lower-tertiary education. Table C.1 shows the rankings of countries in terms of their adjusted $M$ for these two groups, expressed as a deviation from the average adjusted $M$ across the 22 countries. It is evident from Table C.1 that the correlation between the adjusted $M$ for upper tertiary and the adjusted $M$ for lower levels of education is weak. A few countries rank highly on total linkage strength at both the upper tertiary and at lower levels of education: Luxembourg, Croatia, Finland, Greece, and Switzerland are the notable examples. Another set of countries, the Netherlands, Belgium, the UK, and Lithuania, are notable for having weak total linkage strength at both upper-tertiary and lower-levels of education. The rankings of other countries on the adjusted $M$ at the two educational levels are considerably different. Germany and Austria rank high on non-tertiary/lower-tertiary linkage but low on upper-tertiary linkage. The Mediterranean countries of Spain, Portugal, and Italy have low linkage at the non-tertiary/lower-tertiary level but have relatively high linkage at the upper-tertiary level. As we discussed earlier in this paper, the literature on skill formation systems has found it difficult to produce a theoretically unified perspective across the different levels of the educational system. The relatively weak correlation between linkage strength at upper-tertiary and at lower educational levels suggests that this difficulty may arise from weak institutional coupling that produces disparate empirical patterns at these different levels. 
Table C.1: Adjusted M Deviations from Average

\begin{tabular}{|c|c|c|}
\hline Country & non Tertiary/Lower Tertiary & Upper Tertiary \\
\hline \hline Luxembourg & 0.25 & 0.10 \\
\hline Croatia & 0.13 & 0.10 \\
\hline Finland & 0.12 & 0.09 \\
\hline Germany & 0.07 & -0.02 \\
\hline Austria & 0.06 & -.05 \\
\hline Greece & 0.06 & 0.25 \\
\hline Czech Republic & 0.04 & 0.04 \\
\hline Ireland & 0.04 & -0.08 \\
\hline Switzerland & 0.04 & .09 \\
\hline Romania & 0.02 & -0.06 \\
\hline Estonia & 0.02 & 0.01 \\
\hline Latvia & 0.01 & -0.05 \\
\hline France & -0.02 & -0.10 \\
\hline Hungary & -0.03 & 0.02 \\
\hline UK & -0.05 & -0.13 \\
\hline Belgium & -0.07 & -.09 \\
\hline Netherlands & -0.08 & -0.17 \\
\hline Lithuania & -0.08 & -0.04 \\
\hline Spain & -0.08 & 0.03 \\
\hline Portugal & -0.11 & 0.07 \\
\hline Sweden & -0.11 & 0.04 \\
\hline Italy & -0.21 & 0.03 \\
\hline \hline Average & 0.63 & .70 \\
\hline
\end{tabular}

\section{The Heterogeneity of Linkage Strength by Age}

We address in this appendix the question of how different the results would be if we had stratified the data by age, where the data are split according to whether workers are either older than 45 or 45 years old or younger. Table D.1 shows that the local linkage scores based on the full sample correlate very highly with those computed only on the subsamples. The Pearson correlation between the 550 (including general-education non-tertiary workers) local linkage scores computed on the margin-adjusted full sample and those computed only on younger workers is 0.97 . The corresponding correlation using older workers is 0.95 . That said, there are a few noteworthy differences between the rankings of countries in the total $\mathrm{M}$ of the subsamples, which can be seen in Figure D.1.

The most notable differences concern Germany, which has an ideal-typical status in both the CASMIN and the VoC literature. Germany has the highest total linkage strength of any of the 22 countries except for Luxembourg when general-educated non-tertiary 
Table D.1: Correlations between Local Linkage Scores for the Total Sample and for Age Groups

\begin{tabular}{|c|c|c|c|c|c|c|}
\hline & \multicolumn{3}{|c|}{$\begin{array}{c}\text { Including Non-Tertiary } \\
\text { General Education }\end{array}$} & \multicolumn{3}{c|}{$\begin{array}{c}\text { Excluding Non-Tertiary } \\
\text { General Education }\end{array}$} \\
\hline & All & $\leq 45$ & $>45$ & All & $\leq 45$ & $>45$ \\
\hline Margin Unadjusted & & & & & & .969 \\
\hline All Workers & & .971 & .949 & & & .951 \\
\hline Age 45 or Younger & & & .910 & & & \\
\hline & & & & & & \\
\hline Margin Adjusted & & & & & .965 & .946 \\
\hline All Workers & & .968 & .946 & & & .902 \\
\hline Age 45 or Younger & & & .906 & & \\
\hline
\end{tabular}

workers are included, when own-country marginal distributions are included, and when total linkage strength is computed only for workers 45 or younger. Germany drops to fifth after margins are adjusted to a common distribution, reflecting the fact that the German work force is disproportionally located in educational and occupational categories that have high local linkage. Germany's linkage strength drops further, both relative to its linkage strength for its younger workers and relative to other countries, if the focus is on older workers. It has only the sixth highest total linkage strength based on older workers in the sample that includes the general-educated workers. After the data are adjusted to have common marginal distributions for all countries, Germany drops to 14th in the ranking. Both Germany and Switzerland drop out of the top half of the rankings. Austria similarly falls in the rankings though it's total linkage strength remains in the top half of countries.

Evidently, the three countries with German-style "qualification space" skill formation systems have stronger total linkage strength in the occupational placements of their younger workers than of their older workers. While these differences could in principle reflect historical change, we know from the historical analysis in Elbers, Bol, and DiPrete (2021) that the German system has been very stable in its total linkage strength since the 1970s. Those results imply that the differences we see between younger and older workers are being driven by career mobility. This interpretation is consistent with the findings in Elbers, Bol, and DiPrete (2021), who showed that the age differences in linkage strength in Germany are driven largely by the experiences of women. 
Figure D.1: Total Linkage Strength (M) Unadjusted and Margins-Adjusted Data, by Country and Age

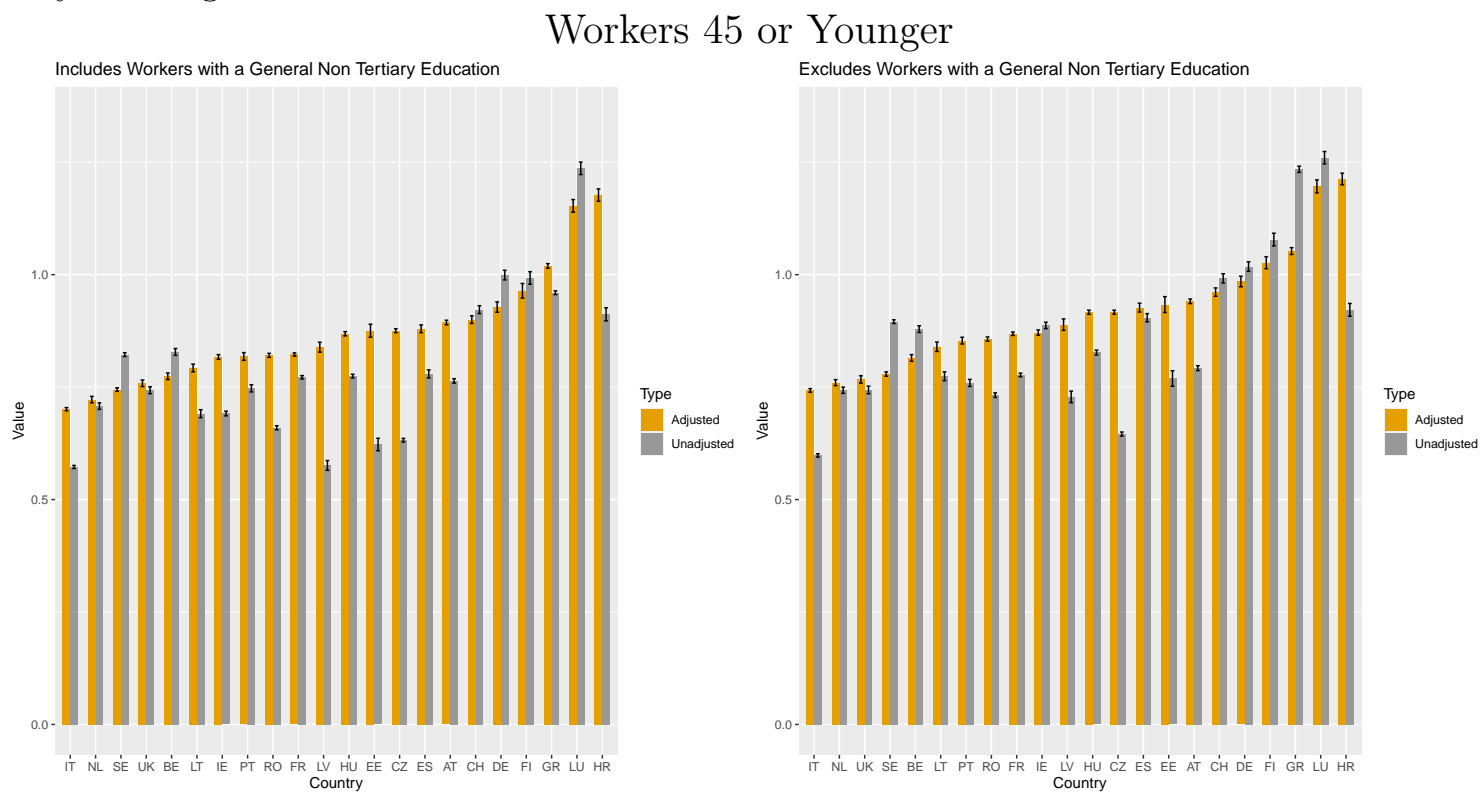

Workers Older than 45

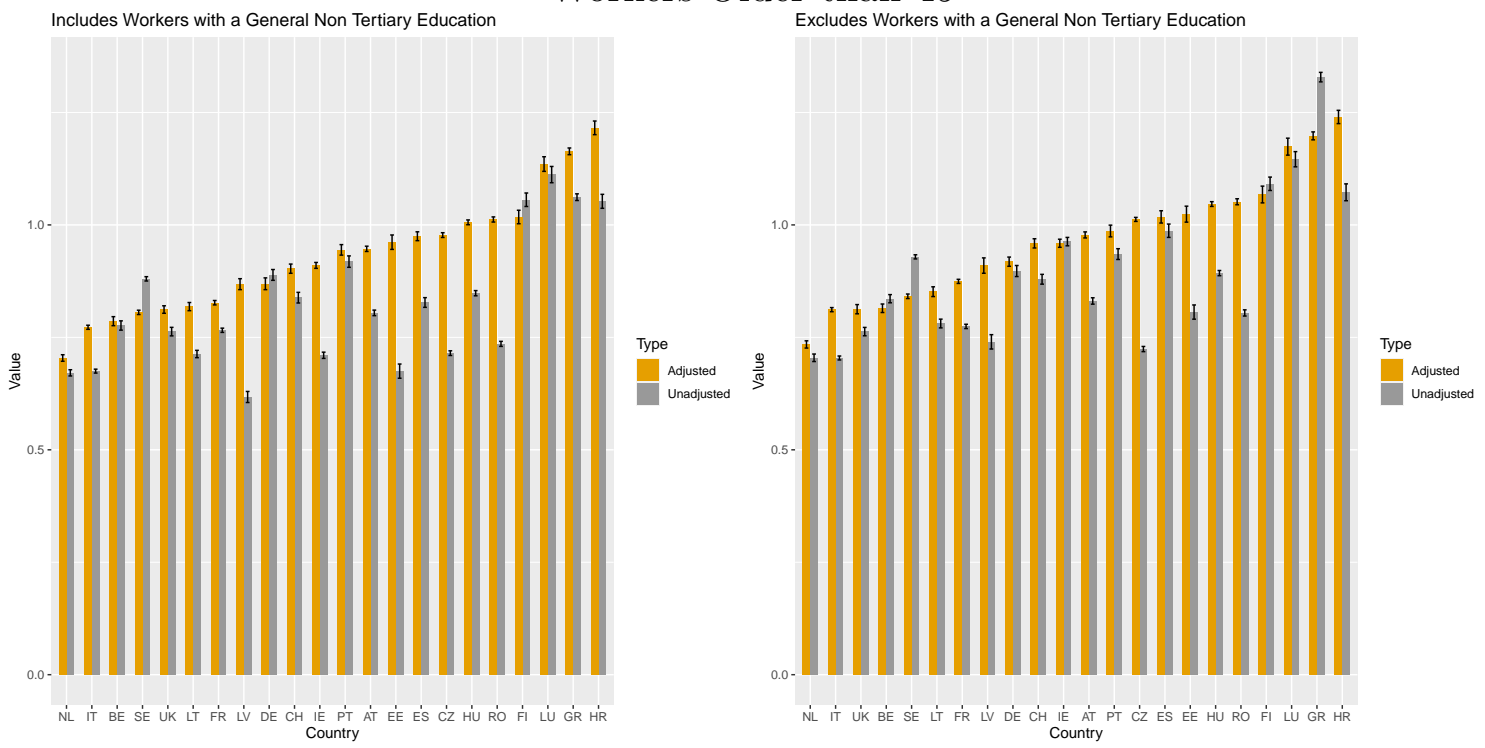

\section{E Is Linkage Strength Affected by the Distribution of Employment Relationships?}

We have established so far that countries differ in their linkage strength, that these differences remain after we take account of differences in the educational and occupational distribution of countries, and that country differences in linkage strength themselves vary de- 
pending upon the particular educational credential of interest. Other scholars (Kalleberg 2018) have found that the proportion of all workers who are permanent, full time workers varies considerably from one country to another. This raises the question of whether country variation in linkage strength might be driving country differences in linkage strength is country differences in the distribution of employment relationships. We first examine whether the local linkage strength of pathways varies with the composition of jobs for employed individuals with that particular educational credential. Table A.1 affirms what others have found (Kalleberg 2018), namely that the proportion of all workers who are permanent, full time workers varies considerably from one country to another. Table E.1 then addresses the relationship between the distribution of employment relationships and the strength of local linkage in an educational pathway. This table shows the results from a fixed effects regression of local linkage strength on the estimated proportion of workers who are full-time permanent (the reference category), part-time permanent, full-time temporary, and part-time temporary including fixed effects for the 22 countries and the 25 level-fields (which equals 550 country-categories), using both the unadjusted and the adjusted local linkage scores.

As can be seen in Table E.1, the distribution of employment relationships among all workers on a given educational pathway in a given country has a clear relationship to the local linkage strength for this pathway. Simply put, the greater the proportion of workers from a given country in a given educational pathway who are permanent and full time, the higher is the local linkage for that educational credential. To got a sense of the importance of employment relationships to local linkage strength, we first make an illustrative comparison of Germany - the ideal type of an occupational space or a coordinated market economy - with the Netherlands, which is typically viewed in the institutional literature (with some cautions) as similar to Germany but whose actual linkage strength is clearly weaker in our calculations, and, at the same time is also a country with very high rates of part-time work. The difference between the unadjusted $M$ for Germany and the Netherlands is 0.23 , and the difference between the adjusted $M$ for these two countries is 0.21 . If we made the strong assumption that the employment relationship adjustments in Table E.1 applied to each of the level-fields, and if we we also assumed that the local linkage score regression could be directly applied to the total M (which, recall, is a weighted sum of the local linkage scores), the regression coefficients in Table E.1 imply that the gap in both total unadjusted $M$ and total adjusted $\mathrm{M}$ would be reduced by .08 for the unadjusted model (about 35\%) and by .11 for the adjusted model (about 52\%).

It should be noted that the coefficients in Table E.1 are not very precisely estimated (for example, they are not all statistically significant). Moreover, the German-Dutch com- 
parison is fairly extreme in the distribution of employment relationships across countries, so we caution against treating this illustrative calculation too literally. To obtain a more rigorous measure across all the countries and educational credentials, we display in Table E.1 the increment to explained variation that can be attributed to the employment relationship categories. Overall, we can explain $67 \%$ of the variation in unadjusted local linkage scores by a combination of fixed effects for the countries, fixed effects for the level-fields, and the variables that measure the distribution of workers across employment relationship categories in the country. Five percent of the total variation $(7.5 \%$ of this $67 \%$ ) can be explained by the employment relationship categories if we give them all the explanatory power that is associated with the country fixed effects; this value shrinks to $2.1 \%$ (3\% of the $67 \%$ ) if we enter them into the equation after the country fixed effects are included in the model. Their explanatory power is reduced when we focus attention on the margins-adjusted local linkage scores instead of the unadjusted scores. Clearly, the variation in job types across the employment relationship categories is implicated in the country variation we see in local linkage strength. At the same time, it would be an exaggeration to conclude that the differences in the distribution of workers across these types of employment relationship is the primary reason for the difference in local linkage scores across countries.

Table E.1: Local Linkage Strength Regressed on the Composition of Employment Relationships

\begin{tabular}{|c|c|c|}
\hline & Unadjusted & Adjusted \\
\hline \hline Proportion part-time permanent & $-.387(.25)$ & $-.513(.19)$ \\
\hline Proportion full-time temporary & $-2.88(.65)$ & $-2.18(.49)$ \\
\hline Proportion part-time temporary & $-2.15(1.1)$ & $-1.23(.82)$ \\
\hline country FE & yes & yes \\
\hline level-field FE & yes & yes \\
\hline $\mathrm{N}$ & 550 & 550 \\
\hline$R^{2}$ & .67 & .73 \\
\hline Increment to $R^{2}$ from employment relationship after country FE & .021 & .018 \\
\hline Increment to $R^{2}$ from employment relationship before country FE & .05 & .026 \\
\hline
\end{tabular}

Note: Standard errors are in parentheses. The "unadjusted" column uses local linkage strength from the unadjusted joint distribution of level-fields and occupations for each country. The "adjusted" column uses local linkage strength estimated from the country tables where the educational and occupational marginal distributions have been adjusted to the distribution for the "super-country" obtained by pooling the data across all the countries in the analysis. The cases are the 25 local linkage scores for each of the 22 countries. Proportions for the employment relationship categories are taken from Table A.1 after adjusting proportions when cases with missing values on work hours or temporary/permanent status are excluded. 


\section{References}

Aggarwal, Charu C., Alexander Hinneburg, and Daniel A. Keim. 2001. "On the Surprising Behavior of Distance Metrics in High Dimensional Space". In Database Theory ICDT 2001, ed. by Gerhard Goos et al., 1973:420-434. Heidelberg: Springer.

Allmendinger, J. 1989. "Educational Systems and Labor Market Outcomes". European Sociological Review 5 (3): 231-250.

Anderson, Karen M., and Dennie Oude Nijhuis. 2011. "The Long Road to Collective Skill Formation in the Netherlands". In The Political Economy of Collective Skill Formation, ed. by Marius R. Busemeyer and Christine Trampusch, 101-125. Oxford: Oxford University Press.

Arum, Richard, Adam Gamoran, and Yossi Shavit. 2007. "More Inclusion than Diversion: Expansion, Differentiation, and Market Structure in Higher Education". In Stratification in Higher Education: A Comparative Study, ed. by R. Arum, A. Gamoran, and Y. Shavit, 1-38. Stanford, CA: Stanford University Press.

Becker, Gary S. 1962. "Investment in Human Capital: A Theoretical Analysis". Journal of Political Economy 70 (5, Part 2): 9-49.

Black, Paul E. 2006. "Manhattan Distance"" Dictionary of Algorithms and Data Structures". http://xlinux. nist. gov/dads//.

Bol, Thijs, and Kim A. Weeden. 2015. "Occupational Closure and Wage Inequality in Germany and the United Kingdom". European Sociological Review 31 (3): 354-369.

Bol, Thijs, et al. 2019. "School-to-Work Linkages, Educational Mismatches, and Labor Market Outcomes". American Sociological Review 84 (2): 275-307.

Broughton, Andrea, et al. 2016. Precarious Employment in Europe: Part I, Patterns, Trends and Policy Strategy. Tech. rep. Brussels: European Union.

Busemeyer, Marius R. 2009. "Asset Specificity, Institutional Complementarities and the Variety of Skill Regimes in Coordinated Market Economies". Socio-Economic Review 7 (3): $375-406$.

- .2014. Skills and Inequality: Partisan Politics and the Political Economy of Education Reforms in Western Welfare States. Cambridge University Press.

Busemeyer, Marius R., and Christine Trampusch. 2011. "The Comparative Political Economy of Collective Skill Formation". In The Political Economy of Collective Skill Formation, ed. by Marius R. Busemeyer and Christine Trampusch, 3-38. Oxford University Press. 
Crouch, Colin. 2005. Capitalist Diversity and Change: Recombinant Governance and Institutional Entrepreneurs. Oxford: Oxford University Press.

Culpepper, Pepper D. 2007. "Small States and Skill Specificity: Austria, Switzerland, and Interemployer Cleavages in Coordinated Capitalism". Comparative Political Studies 40 (6): 611-637.

de Graaf-Zijl, Marloes, Gerard J. Van den Berg, and Arjan Heyma. 2011. "Stepping Stones for the Unemployed: The Effect of Temporary Jobs on the Duration until (Regular) Work". Journal of Population Economics 24 (1): 107-139.

DiPrete, Thomas A., et al. 2017. "School-to-Work Linkages in the United States, Germany, and France". American Journal of Sociology 122 (6): 1869-1938.

Elbers, Benjamin. 2021. "A Method for Studying Differences in Segregation Across Time and Space". Sociological Methods \& Research online:https://doi-org.ezproxy.cul.columbia.edu/ $10.1177 / 0049124121986204$.

Elbers, Benjamin, Thijs Bol, and Thomas A DiPrete. 2021. "Training Regimes and Skill Formation in France and Germany: An Analysis of Change between 1970 and 2010". Social Forces 99 (3): 1113-1145.

Eurostat. 2012. Quality Report of the European Union Labour Force Survey, 2010. Luxembourg: European Commission.

Figari, Francesco, and Gerlinde Verbist. 2014. "The Redistributive Effect and Progressivity of Taxes Revisited: An International Comparison across the European Union". FinanzArchiv 70 (3): 405.

Gift, Thomas, and Erik Wibbels. 2014. "Reading, Writing, and the Regrettable Status of Education Research in Comparative Politics" [inlangen]. Annual Review of Political Science 17, no. 1 (): 291-312.

Glyn, Andrew. 2007. Capitalism Unleashed: Finance, Globalization, and Welfare. Oxford: Oxford University Press.

Goedegebuure, L. C. J., et al. 1996. "On Diversity, Differentiation and Convergence". In In: V. Lynn Meek, L. Goedegebuure, O. Kivinen and R. Rinne (Eds.), The Mockers and Mocked: Comparative Perspectives on Differentiation, Convergence and Diversity in Higher Education, 2-16. Oxford: Pergamon.

Gonon, Philipp, and Markus Maurer. 2011. "Educational Policy Actors as Stakeholders in the Development of the Collective Skill System: The Case of Switzerland". In The Political Economy of Collective Skill Formation, ed. by Marius R. Busemeyer and Christine Trampusch, 126-149. Oxford University Press. 
Hall, Peter A., and Daniel W. Gingerich. 2009. "Varieties of Capitalism and Institutional Complementarities in the Political Economy: An Empirical Analysis". British Journal of Political Science 39 (3): 449-482.

Hall, Peter A., and David Soskice. 2001a. "An Introduction to Varieties of Capitalism". In Varieties of Capitalism: The Institutional Foundations of Comparative Advantage. Ed. by Peter A Hall and David W Soskice, 1-67. Oxford: Oxford University Press.

Hall, Peter A, and David W Soskice. 2001b. Varieties of Capitalism: The Institutional Foundations of Comparative Advantage. Oxford University Press.

Hanushek, Eric A., et al. 2017. "General Education, Vocational Education, and LaborMarket Outcomes over the Lifecycle". Journal of Human Resources 52 (1): 48-87.

Hicks, Alexander, and Lane Kenworthy. 1998. "Cooperation and Political Economic Performance in Affluent Democratic Capitalism". American Journal of Sociology 103 (6): 1631-1672.

Jerrim, John, and Lindsey Macmillan. 2015. "Income inequality, intergenerational mobility, and the great Gatsby Curve: Is education the key?" Social Forces 94 (2): 505-533.

Kalleberg, Arne L. 2011. Good Jobs, Bad Jobs: The Rise of Polarized and Precarious Employment Systems in the United States, 1970s-2000s. New York: Russell Sage Foundation.

— . 2018. Precarious Lives: Job Insecurity and Well-Being in Rich Democracies. Cambridge, UK: Polity Press.

Kenworthy, Lane. 2006. "Institutional Coherence and Macroeconomic Performance". SocioEconomic Review 4 (1): 69-91.

Kleiner, Morris M. 2016. "Battling over Jobs: Occupational Licensing in Health Care". American Economic Review 106 (5): 165-70.

— . 2006. Licensing Occupations: Ensuring Quality or Restricting Competition? Kalamzoo, MI: WE Upjohn Institute.

Kleiner, Morris M., and Alan B. Krueger. 2013. "Analyzing the Extent and Influence of Occupational Licensing on the Labor Market". Journal of Labor Economics 31 (S1): S173-S202.

Koumenta, Maria, and Mario Pagliero. 2017. Measuring Prevalence and Labour Market Impacts of Occupational Regulation in the EU. Tech. rep. Brussels: European Commission. 
Maurice, M., F. Sellier, and J. J Silvestre. 1986. The Social Foundations of Industrial Power: A Comparison of France and Germany. Cambridge, MA: The MIT Press.

Mora, Ricardo, and Javier Ruiz-Castillo. 2011. "Entropy-Based Segregation Indices". Sociological Methodology 41 (1): 159-194.

Müller, Walter, and Yossi Shavit. 1998. "The Institutional Embeddedness of the Stratification Process: A Comparative Study of Qualifications and Occupations in Thirteen Countries". In From School to Work: A Comparative Study of Educational Qualifications and Occupational Destinations, ed. by Yossi Shavit and Walter Müller, 1-48. Oxford: Oxford: Clarendon Press.

Nikolai, Rita, and Christian Ebner. 2011. "The Link between Vocational Training and Higher Education in Switzerland, Austria, and Germany". In The Political Economy of Collective Skill Formation, ed. by Marius R. Busemeyer and Christine Trampusch, 234-258. Oxford: Oxford University Press.

Organisation for Economic Co-operation and Development and Organisation for Economic Co-operation and Development, eds. 2015. In It Together: Why Less Inequality Benefits All. Paris: OECD Publishing.

Pfeffer, F. T. 2008. "Persistent Inequality in Educational Attainment and Its Institutional Context". European Sociological Review 24 (5): 543-565.

Powell, Justin JW, Nadine Bernhard, and Lukas Graf. 2012. "The Emergent European Model in Skill Formation: Comparing Higher Education and Vocational Training in the Bologna and Copenhagen Processes". Sociology of Education 85 (3): 240-258.

Powell, Justin JW, and Heike Solga. 2010. "Analyzing the Nexus of Higher Education and Vocational Training in Europe: A Comparative-Institutional Framework". Studies in Higher Education 35 (6): 705-721.

Reardon, S. F, and G. Firebaugh. 2002. "Measures of Multigroup Segregation". Sociological Methodology 32 (1): 33-67.

Redbird, Beth. 2017. "The New Closed Shop? The Economic and Structural Effects of Occupational Licensure". American Sociological Review 82 (3): 600-624.

Roksa, Josipa, and Tania Levey. 2010. "What Can You Do with That Degree?: College Major and Occupational Status of College Graduates over Time". Social Forces 89 (2): $389-415$.

Rözer, Jesper, and Herman G van de Werfhorst. 2020. "Three Worlds of Vocational Education: Specialized and General Craftsmanship in France, Germany, and The Netherlands". European Sociological Review (): jcaa025. 
Shavit, Yossi, Richard Arum, and Adam Gamoran. 2007. Stratification in Higher Education: A Comparative Study. First. Stanford, Calif.: Stanford University Press.

Shavit, Yossi, and Walter Müller, eds. 1998. From School to Work: A Comparative Study of Educational Qualifications and Occupational Destinations. Oxford: Clarendon Press.

Solga, Heike. 2012. "Bildung Und Materielle Ungleichheiten. Der Investive Sozialstaat Auf Dem Prüfstand". In Soziologische Bildungsforschung, ed. by Rolf Becker and Heike Solga, 459-487. Heidelberg: Springer.

Streeck, Wolfgang. 2009. Re-Forming Capitalism: Institutional Change in the German Political Economy. Oxford: Oxford University Press.

Theil, H. 1972. Statistical Decomposition Analysis: With Applications in the Social and Administrative Sciences. Amsterdam: North-Holland.

Theil, H., and A. J Finizza. 1971. "A Note on the Measurement of Racial Integration of Schools by Means of Informational Concepts".

Thelen, Kathleen. 2007. "Contemporary Challenges to the German Vocational Training System". Regulation \& Governance 1 (3): 247-260.

— . 2012. "Varieties of Capitalism: Trajectories of Liberalization and the New Politics of Social Solidarity". Annual Review of Political Science 15 (1): 137-159.

— . 2001. "Varieties of Labor Politics in the Developed Democracies". Varieties of capitalism: The institutional foundations of comparative advantage 71:76-92.

UNESCO. 2006. ISCED 199\%: International Standard Classification of Education. Tech. rep. New York: United Nations Educational, Scientific, and Cultural Organization.

Van de Werfhorst, H. G. 2011. "Skill and education effects on earnings in 18 Countries: The role of national educational institutions". Social Science Research.

Verbakel, Ellen, and Thomas A. DiPrete. 2008. "The Value of Non-Work Time in CrossNational Quality of Life Comparisons: The Case of the United States vs. The Netherlands". Social Forces 87 (2): 679-712.

Weeden, Kim A. 2002. "Why Do Some Occupations Pay More than Others? Social Closure and Earnings Inequality in the United States". American Journal of Sociology 108 (1): 55-101.

Werfhorst, H. G van de. 2002. "Fields of study, acquired skills and the wage benefit from a matching job". Acta Sociologica 45 (4): 286-303. 
Witte, James C., and Arne L. Kalleberg. 1995. "Matching training and jobs: The fit between vocational education and employment in the German labour market". European Sociological Review 11 (3): 293-317.

Wolbers, Maarten HJ. 2003. "Job Mismatches and their Labour-Market Effects among School-Leavers in Europe”. European Sociological Review 19 (3): 249-266. 